\title{
Synthesis, DFT Study and Bioactivity Evaluation of New Butanoic Acid Derivatives as Antiviral Agents
}

\author{
Hora Alhosseini Almodarresiyeh ${ }^{1(\mathbb{D})}$, Siyamak Shahab ${ }^{2,3,4}(\mathbb{D})$, Sadegh Kaviani ${ }^{5, *(\mathbb{D})}$, \\ Masoome Sheikhi $^{6}$ (D), Dina V. Lopatik ${ }^{4}$ (D) , Zoya I. Kuvaeva ${ }^{4}$ (D) , Helen G. Karankevich ${ }^{4}$ (D) \\ 1 Department of Materials Science and Engineering, School of Engineering, Meybod University, 89616-99557, Meybod, \\ Yazd, Iran \\ 2 Belarusian State University, ISEI BSU, Minsk, Republic of Belarus \\ 3 Institute of Chemistry of New Materials, National Academy of Sciences of Belarus, 36 Skarina Str., Minsk 220141, \\ Republic of Belarus \\ 4 Institute of Physical Organic Chemistry, National Academy of Sciences of Belarus,13 Surganov Str., Minsk 220072, \\ Republic of Belarus \\ 5 Research Center for Modeling and Computational Sciences, Department of Chemistry, Faculty of Science, Ferdowsi \\ University of Mashhad, Mashhad 9177948974, Iran \\ 6 Young Researchers and Elite Club, Gorgan Branch, Islamic Azad University, Gorgan, Iran \\ * Correspondence: kaviani.sadegh@mail.um.ac.ir (S.K.);
}

Scopus Author ID: 57190261707

Received: 31.05.2021; Revised: 10.07.2021; Accepted: 14.07.2021; Published: 9.08.2021

\begin{abstract}
In the present work, at first, density functional theory (DFT) calculations were utilized for the molecular design of the four new butanoic acid derivatives at B3LYP/6-31+G(d) level of theory. After DFT calculations, synthesis, FT-IR, 1H NMR, and 13C NMR spectra of corresponding molecules were presented. The NBO analysis and electronic properties of the four new synthesized butanoic acid $(1,2,3,4)$ were carried out to compare their stability and reactivity. Finally, the values of octanol/water partition coefficient (miLogP), the molecular polar surface area (TPSA), the number of atoms of the molecule ( $\mathrm{n}_{\text {atoms }}$ ), the number of hydrogen bond acceptors (nON), the number of hydrogen bond donors $(\mathrm{nOHNH})$, the number of violations of the Ro5 ( $\left.\mathrm{n}_{\text {violations }}\right)$, the number of rotatable bonds $\left(\mathrm{n}_{\text {rotb }}\right)$, the molecular volume $(\mathrm{Vm})$, the molecular weight (MW) and bioactivity scores were estimated and discussed.
\end{abstract}

Keywords: butanoic acid derivatives; synthesis; DFT; bioactivity; pharmacokinetic properties.

(C) 2021 by the authors. This article is an open-access article distributed under the terms and conditions of the Creative Commons Attribution (CC BY) license (https://creativecommons.org/licenses/by/4.0/).

\section{Introduction}

Butanoic acid is a short-chain fatty acid that has been utilized as an antiviral agent to prevent colorectal cancer [1] and various types of diseases [2-5]. Its anti-tumor function is mainly attributed to histone deacetylase (HDAC) inhibitory action, which affects colon cells through acting as a ligand for $G$ protein-coupled receptor 109A (GPR109A) [6-8]. Nevertheless, the short half-life of butanoic acid limits its therapeutic function in the apoptosis of cancer cells [9]. Nowadays, discovering a new drug in the shortest possible time has become a focal point in medicine. The need for novel and better drugs with more selectivity and less toxicity are major properties for designing a molecule [10-13].

Molecular modeling has been played the main role in the fields of chemical, material, and biological sciences [14]. It has largely been helped in understanding the molecular structure, geometrical and electronic characteristics of organic compounds. This information 
can provide a perspective into the chemical mechanisms, reaction pathways, and designing of newer molecules $[15,16]$. Dentistry Functional Theory (DFT) is routinely used to evaluate the electronic and geometrical properties, which has been made significant advances in the synthesis of organic materials and novel chemical reaction and mechanistic studies [17-20].

The correlations between experimental and quantum calculations data have been solved a vast range of organic problems. For example, the comparative studies between theoretical and experimental data of 5-(4-chlorophenyl)-2-amino-1,3,4-thiadiazole, a compound with antiproliferative activity, were conducted by Kerru et al. [10]. The optimized geometry parameters of this compound were carried out using B3LYP functional within 6-31+G(d,p) and 6$311+\mathrm{G}(\mathrm{d}, \mathrm{p})$ basis sets, and conceivable correlations were investigated between observed and theoretical data. Also, quantum chemistry methods based on DFT can predict new organic molecules and calculate their UV-Vis, IR, and NMR spectra [21-31]. Four new azomethine dyes were designed and calculated their geometrical parameters, UV/Vis, and IR spectra by DFT (PBE1PBE/6-31+G(d) level of theory) [32]. The experimental and calculated IR and $\mathrm{UV} / \mathrm{V}$ is spectra of the title compounds are found to be in good agreement with each other. The vibrational spectra of pharmaceutically important molecule Ethyl 2-(4-benzoyl-2, 5dimethylphenoxy) acetate (EBDA) have been performed by Amalanathan et al. using FTIR, FT-Raman analysis and DFT (B3LYP) method using 6-311++G(d,p) basis sets [16]. A comparison of the results indicates a good agreement between the experimental and theoretical data. Ali et al. carried out a DFT study on the spectroscopic and structural analysis of pDimethylaminoazobenzene (DMAB) to predict its reactivity [33]. DFT and TD-DFT studies on Azure A chloride showed that the experimental data are in excellent compromise with theoretical results [22].

The study under consideration represents a theoretical and experimental analysis of the structural and spectroscopic properties of four new butanoic acid derivatives. The compounds 1, 2, 3, and 4, as shown in Figure 1, were designed and calculated their geometrical parameters. Natural Bond Orbital (NBO) analysis has been performed to identify the possible intra- and intermolecular interactions present in mentioned compounds. The HOMO-LUMO energies were calculated for analyzing the intramolecular charge transfer. Electrostatic potential analysis has also been made to identify the mapping surface of the compounds. The studied compounds were synthesized and characterized by FT-IR, ${ }^{1} \mathrm{H}$ NMR, and ${ }^{13} \mathrm{C}$ NMR spectroscopy.

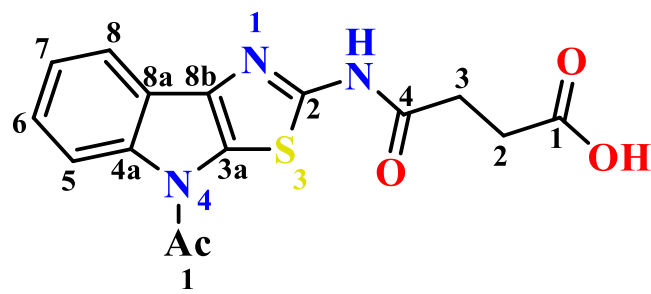

4-((4-acetyl-4H-thiazolo[5,4-b]indol-2-yl)amino)-4-oxobutanoic acid (1)

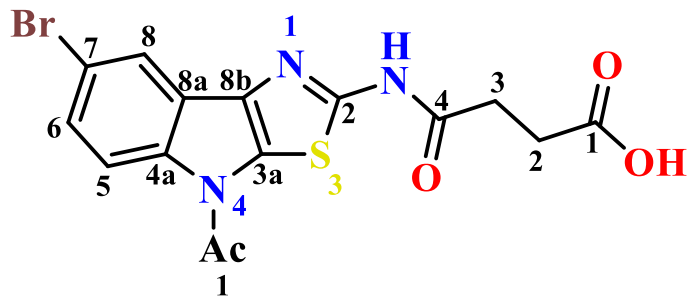

4-((4-acetyl-7-bromo-4H-thiazolo[5,4-b]indol-2-yl)amino)-4-oxobutanoic acid (2) 


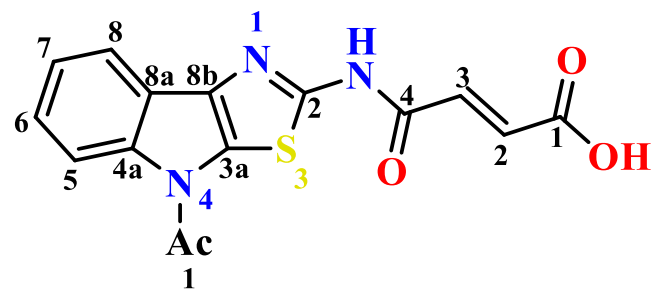

(E)-4-((4-acetyl-4H-thiazolo[5,4-b]indol-2-yl)amino)-4-oxobut-2-enoic acid (3)

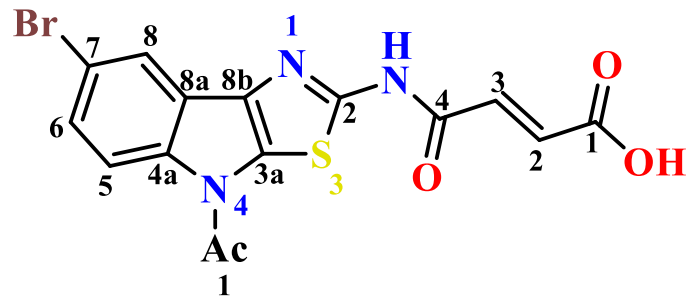

(E)-4-((4-acetyl-7-bromo-4H-thiazolo[5,4-b]indol-2-yl)amino)-4-oxobut-2-enoic acid (4)

Figure 1. Chemical structure of four new butanoic acid derivatives.

\section{Materials and methods}

\subsection{Computational methods.}

All of the calculations were carried out using the Gaussian 09 software package [34]. Geometry optimizations are performed by the DFT method using B3LYP/6-31+G(d) basis set in water solution. Harmonic vibrational frequencies were computed to characterize the stationary points as minima and zero-point vibrational energies (minima with no negative force constant). The solvent effect was carried out by using the SCRF method [35]. The optimization calculations provide thermodynamic quantities such as enthalpies and Gibbs free energies at 298.15 K and 1.0 atm. Dipole moment (D) as well as geometrical parameters such as bond length $(\AA)$ and symmetry, were evaluated. The nucleophilicity index $(\mathrm{N})$, chemical potential $(\mu)$, and electrophilic index $(\omega)$ were computed by Eqs 1-3 [36-38].

$\mathrm{N}=$ Еномо-Еномо

$\mu=\mathrm{E}_{\text {HOMO }}+\mathrm{E}_{\mathrm{LUMO}}$

$\mu^{2} / 2 \eta$

To obtain NMR spectra, we performed the calculations using GIAO method [39]. The redistribution of electron density (ED) in different bonding and anti-bonding orbitals were analyzed by natural bond orbital (NBO) analysis [40]. The values of miLogP, TPSA, $\mathrm{n}_{\text {atoms, }}$ $\mathrm{nON}, \mathrm{nOHNH}, \mathrm{n}_{\text {violations, }} \mathrm{n}_{\text {rotb }}, \mathrm{V}_{\mathrm{m}}, \mathrm{MW}$, and bioactivity scores were calculated by Molinspiration software [41].

\subsection{Molecular properties and drug-likeness.}

Molecular properties and bioavailability were estimated by calculating the properties that constitute Lipinski [42], Ghose [43], and Veber [44] rules using Molinspiration software. They are correlated to molecular descriptors like molecular weight, hydrogen bond and accepters in molecules, partition coefficient $(\log \mathrm{P})$. Bioactivity of the studied compounds was predicted by estimation of the activity value for G protein-coupled receptors (GPCR ligand), ion channel modulator, nuclear receptor ligand, kinase, and protease inhibitors. 


\subsection{Reagent and apparatus.}

All materials and reagents were commercially available and used without any purification. FT-IR spectrum of title structures was measured by a spectrophotometer of Protégé 460 (Nicolet, US) [45]. The experimental FT-IR spectrum was recorded by KBr pellet method with spectral resolution $2 \mathrm{~cm}^{-1}$ [46]. ${ }^{1} \mathrm{H}$ NMR and ${ }^{13} \mathrm{C}$ NMR spectra were recorded in DMSO-d6 by NMR AVANCE-500 spectrometer (Bruker, Germany) [47] with a working frequency of $600 \mathrm{~Hz}(1 \mathrm{H})$.

\subsection{Synthesis.}

Compounds 1-4 are prepared by heating of 2-amino-4-acetylthiazolo[5,4-b]-indole and 2-amino-4-acetyl-7-bromothiazolo[5,4-b]indole with succinic anhydride and maleic anhydride in dimethylformamide. The results of precipitate were filtered off and washed with hot ethyl alcohol.

\section{4-((4-acetyl-4H-thiazolo [5,4-b] indol-2-yl)amino)-4-oxobutanoic acid (1)}

The suspension of $7.0 \mathrm{~g}(0.03 \mathrm{~mol})$ of 2-amino-4-acetylthiazolo[5,4-b]indole and $6.0 \mathrm{~g}$ $(0.06 \mathrm{~mol})$ of succinic anhydride was heated in $45 \mathrm{ml}$ of DMFA under stirring for $50 \mathrm{~min}$ at $125-133^{\circ} \mathrm{C}$. After cooling to room temperature, the precipitate was separated, washed with hot ethyl alcohol, and recrystallized from the mixture DMFA:n-butanol $(2: 1)$. The product of grayish-white color that melts at $310-315^{\circ} \mathrm{C}$ was obtained. The yield is $45 \%$. Analysis calc. $\%$ for $\mathrm{C}_{15} \mathrm{H}_{13} \mathrm{~N}_{3} \mathrm{O}_{4} \mathrm{~S}$, \%: C 54.40, H 3.90, N 12.70, S 9.72. Found, \%: C 54.36, H 3.87, N 12.64, S 9.70. FT-IR (KBr pellet, $\left.\mathrm{cm}^{-1}\right): v, \mathrm{~cm}^{-1}: 2932\left(-\mathrm{CH}_{2}-\mathrm{CH}_{2}-\right), 1685$ (COOH), 1569 (amide II), 1569 (pyrrole), 1371 and 1371 (-CH-), 744 (aroma). ${ }^{1} \mathrm{H}$ NMR spectrum (DMSO-d6), $\delta$ ppm, J, $\mathrm{Hz}: 2.60 \mathrm{t}\left(2 \mathrm{H}, \mathrm{CH}_{2} \mathrm{CO}\right), 2.72 \mathrm{t}(2 \mathrm{H}, \mathrm{CH} 2 \mathrm{C}(\mathrm{O}) \mathrm{O}), 2.82 \mathrm{~s}\left(3 \mathrm{H}, \mathrm{CH}_{3}\right), 7.39 \mathrm{td}\left(1 \mathrm{H}_{,} \mathrm{H}^{7}\right), 7.41 \mathrm{td}$ $\left(1 \mathrm{H}, \mathrm{H}^{6}\right), 7.78 \mathrm{dd}\left(1 \mathrm{H}, \mathrm{H}^{5}\right), 7.97$ brs $\left(1 \mathrm{H}, \mathrm{H}^{8}\right), 12.40$ brs $(2 \mathrm{H}, \mathrm{NH}, \mathrm{OH})$.

\section{4-((4-acetyl-7-bromo-4H-thiazolo[5,4-b]indol-2-yl)amino)-4-oxobutanoicacid (2)}

The solution of $6.2 \mathrm{~g}(0.02 \mathrm{~mol})$ of 2-amino-4-acetyl-7-bromothiazolo[5,4-b]indole and $4.0 \mathrm{~g}(0.04 \mathrm{~mol})$ of succinic anhydride was heated in $40 \mathrm{ml}$ of DMFA under stirring for 1 hour at $130-145^{\circ} \mathrm{C}$. The reaction mixture was cooled, and the precipitate was separated. The product was washed with ethyl alcohol, heated to $40-45^{\circ} \mathrm{C}$, and dried. $2.4 \mathrm{~g}$ of a white substance that melts at $>320^{\circ} \mathrm{C}$ was obtained. Analysis calc. $\%$ for $\mathrm{C}_{15} \mathrm{H}_{12} \mathrm{BrN}_{3} \mathrm{O}_{4} \mathrm{~S}, \%$ : C 43.90, H 2.92, N 10.24, S 7.80. Found, \%: C 43.88, H 2.36, N 9.70, S 7.79. FT-IR (KBr pellet, $\left.\mathrm{cm}^{-1}\right)$ : v, $\mathrm{cm}^{-1}$ : 2925 (- $\left.\mathrm{CH}_{2}-\mathrm{CH}_{2}-\right), 1698(\mathrm{COOH}), 1678$ (amide I), 1561, 15049 (pyrrole), 1435 and 1367 ($\mathrm{CH}-$ ), 1294, 1242, 1205, 986 (aroma). ${ }^{1} \mathrm{H}$ NMR spectrum (DMSO-d6), $\delta$ ppm, J, Hz: $2.60 \mathrm{t}$ $\left(2 \mathrm{H}, \mathrm{CH}_{2} \mathrm{CO}\right), 2.72 \mathrm{t}(2 \mathrm{H}, \mathrm{CH} 2 \mathrm{C}(\mathrm{O}) \mathrm{O}), 2.77 \mathrm{~s}\left(3 \mathrm{H}, \mathrm{CH}_{3}\right), 7.48 \mathrm{dd}\left(1 \mathrm{H}, \mathrm{H}^{6}\right), 7.81 \mathrm{~s}\left(1 \mathrm{H}, \mathrm{H}^{8}\right)$, $7.78 \mathrm{dd}\left(1 \mathrm{H}, \mathrm{H}^{5}\right), 7.90$ brs $\left(1 \mathrm{H}, \mathrm{H}^{5}\right), 12.22$ brs $(1 \mathrm{H}, \mathrm{OH}), 12.44$ brs $(1 \mathrm{H}, \mathrm{NH})$.

\section{4-((4-acetyl-4H-thiazolo[5,4-b]indol-2-yl)amino)-4-oxobut-2-enoicacid (3)}

The suspension of $7.0 \mathrm{~g}(0.03 \mathrm{~mol})$ of 2-amino-4-acetylthiazolo[5,4-b]indole and $9.0 \mathrm{~g}$ $(0.09 \mathrm{~mol})$ of maleic anhydride was heated in $40 \mathrm{ml}$ of DMFA under stirring for $2.5 \mathrm{~h}$ at 110 $120^{\circ} \mathrm{C}$. After cooling the reaction mixture, the precipitate was separated and washed with hot ethyl alcohol. A yellow powdery substance with a melting point of $308-310^{\circ} \mathrm{C}$ was obtained. The yield is $83 \%$. Analysis calc. \% for $\mathrm{C}_{15} \mathrm{H}_{8} \mathrm{~N}_{3} \mathrm{O}_{3} \mathrm{~S}, \%$ : C 54.70, H 3.34, N 12.80, S 9.73. 
Found, \%: C 54.57, H 3.38, N 11.95, S 11.95. FT-IR (KBr pellet, $\left.\mathrm{cm}^{-1}\right): v, \mathrm{~cm}^{-1}: 1682(\mathrm{C}=\mathrm{O})$, 11578 ( amide II), 1500 (pyrrole), 1434 (-CH=CH-), 1373 (-CH-), 1337, 1291 (-COO-), 742 (aroma). ${ }^{1} \mathrm{H}$ NMR spectrum (DMSO- $\left.d_{6}\right), \delta$ ppm, J, Hz: $2.82 \mathrm{~s}\left(3 \mathrm{H},-\mathrm{CH}_{3}\right), 6.79 \mathrm{~d}(1 \mathrm{H}, \mathrm{CHCO})$, $7.17 \mathrm{~d}(1 \mathrm{H}, \mathrm{CHC}(\mathrm{O}) \mathrm{O}), 7.39$ brs $\left(2 \mathrm{H}, \mathrm{H}^{6}, \mathrm{H}^{7}\right), 7.79$ brs $\left(1 \mathrm{H}, \mathrm{H}^{5}\right), 7.90$ brs $\left(1 \mathrm{H}, \mathrm{H}^{8}\right), 12.95$ brs $(2 \mathrm{H}, \mathrm{NH}, \mathrm{OH})$.

\section{4-((4-acetyl-7-bromo-4H-thiazolo[5,4-b]indol-2-yl)amino)-4-oxobut-2-enoic acid (4)}

The suspension of $5.0 \mathrm{~g}(0.016 \mathrm{~mol})$ of 2-amino-4-acetyl-7-bromothiazolo[5,4-b]indole and $5.0 \mathrm{~g}(0.05 \mathrm{~mol})$ of maleic anhydride was heated in $30 \mathrm{ml}$ of DMFA under stirring for 2.5 $\mathrm{h}$ at $110-120^{\circ} \mathrm{C}$, after cooling of the reaction mixture, the residue was filtered off and washed with hot ethyl alcohol. After air-drying, a yellow powdery substance with a melting point of $312{ }^{\circ} \mathrm{C}$ was obtained. The yield is $70 \%$. Analysis calc. $\%$ for $\mathrm{C}_{15} \mathrm{H}_{10} \mathrm{BrN}_{3} \mathrm{O}_{4} \mathrm{~S}, \%$ : C $44.12, \mathrm{H}$ 2.45, N 10.73, S 7.84. Found, \%: C 43.94, H 2.47, N 10.08, S 7.90. FT-IR (KBr pellet, $\mathrm{cm}^{-1}$ ): $v, \mathrm{~cm}^{-1}: 1700(\mathrm{COOH}), 1639$ (amide I), 1585 (amide II), 1505 (pyrrole), 1432, 1396, 1372 ($\mathrm{CH}-$ ) , 1343, 1264, 1206 (-CH=CH-), 792, 734 (aroma). ${ }^{1} \mathrm{H}$ NMR spectrum (DMSO- $d_{6}$ ), $\delta$ ppm, J, Hz: $2.82 \mathrm{~s}\left(3 \mathrm{H},-\mathrm{CH}_{3}\right), 6.50 \mathrm{~d}(1 \mathrm{H}, \mathrm{CHCO}), 6.53 \mathrm{~d}(1 \mathrm{H}, \mathrm{CHC}(\mathrm{O}) \mathrm{O}), 7.53 \mathrm{dd}\left(1 \mathrm{H}, \mathrm{H}^{6}\right), 7.88$ $\mathrm{d}\left(1 \mathrm{H}, \mathrm{H}^{8}\right), 7.90$ brs $\left(1 \mathrm{H}, \mathrm{H}^{5}\right), 12.90$ brs $(2 \mathrm{H}, \mathrm{NH}, \mathrm{OH})$.

\section{Results and Discussion}

\subsection{Optimized structures and their Electronic properties.}

We have compared and contrasted the properties of compounds 1-4, at B3LYP/6$31+G(d)$ level of theory in the solvent water. All scrutinized structures turn out as minima on their potential energy surfaces for showing no imaginary frequency. The optimized molecular structures and bond lengths of the mentioned compounds are demonstrated in Figure 2. All structures display similar structural parameters such as bond lengths, and their geometry possesses $\mathrm{C}_{1}$ point group symmetry. Typically, introducing a bromine atom in the aromatic ring, the changes in the atomic bond distances near the substituted positions are $0.01 \AA$. Compound 2 shows the highest dipole moment (6.82 Debye). Overall, the order of dipole moment appears as follows: $2>1>3>4$.

The different binding affinities could be elucidated according to the frontier orbitals and electrostatic potential (ESP) maps [48]. Nucleophilicity values show conspicuous correlations with the corresponding electrostatic potential maps (ESP) for 1, 2, 3, and 4, which are consistent with nucleophilicity values (Figure 3). The red and blue regions on the scale bar indicate the lowest and highest electrostatic potential energy values, respectively. The ESP maps of our structures reveal their charge distribution, size, and shape. The red-colored oxygen atoms show the most electron-rich regions of mentioned compounds. Therefore, these parts may also bind to receptors through electrostatic interaction or hydrogen bonding. Interestingly, ESP maps qualitatively depict higher electron density on the oxygen atom of all compounds. 


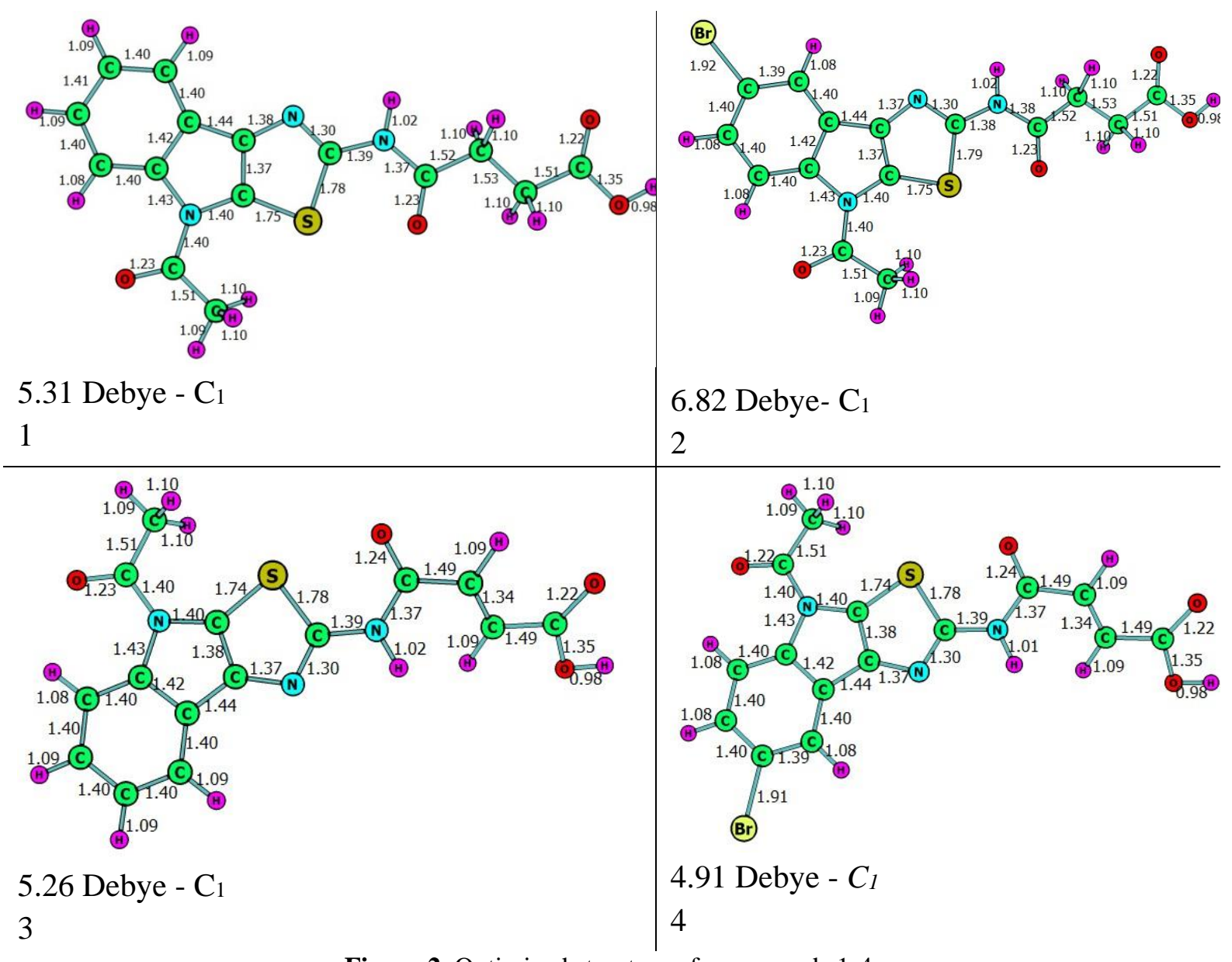

Figure 2. Optimized structure of compounds 1-4.
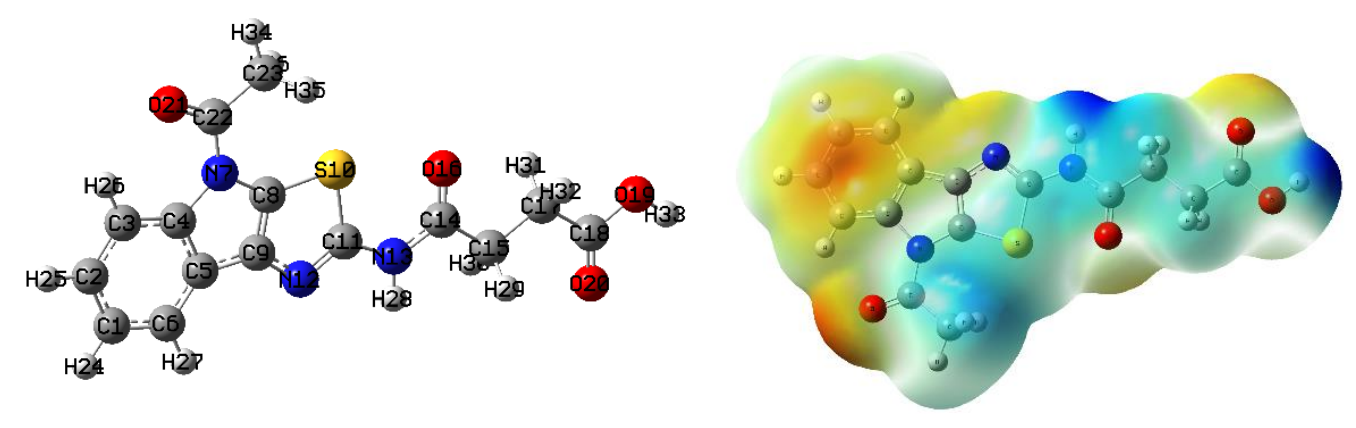

1
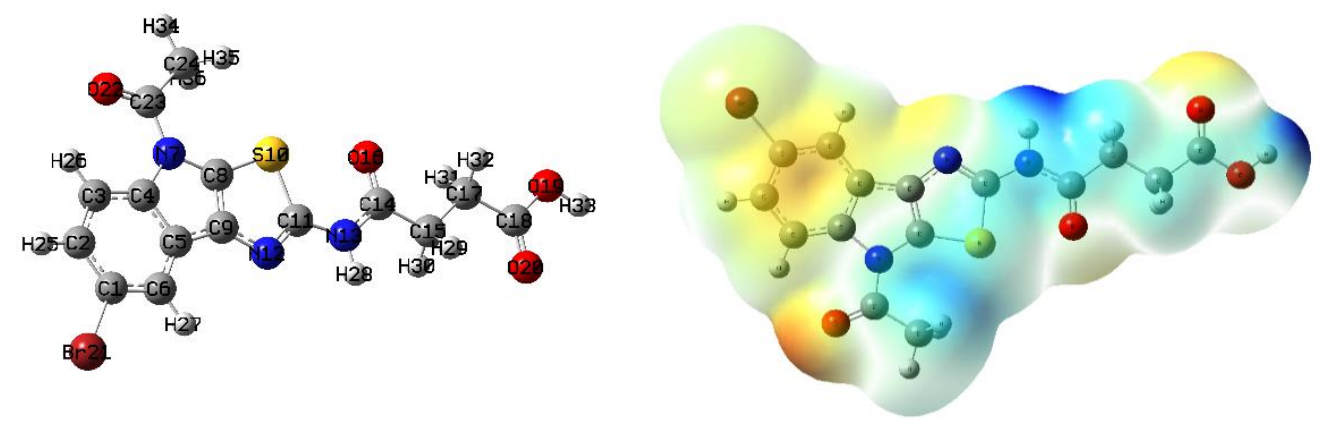

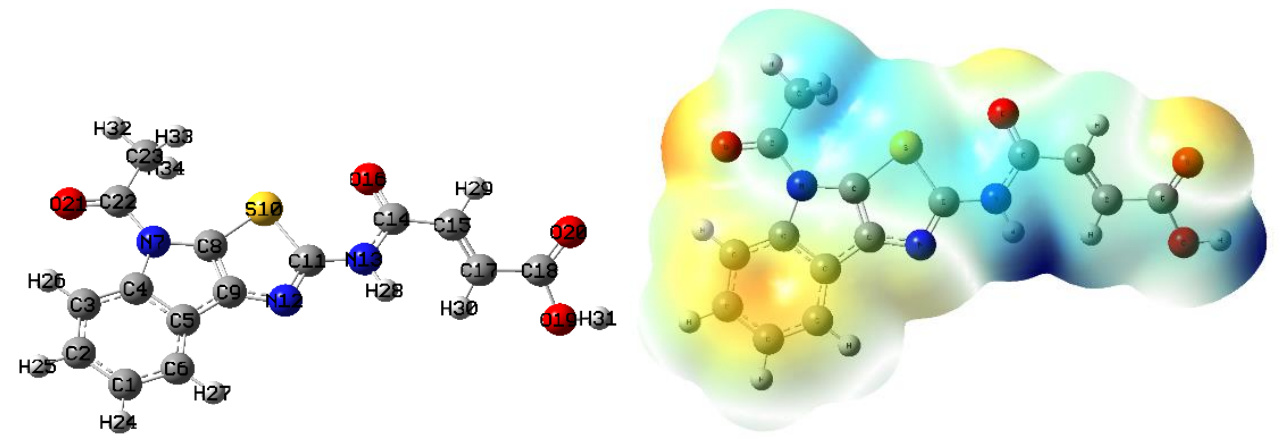

3
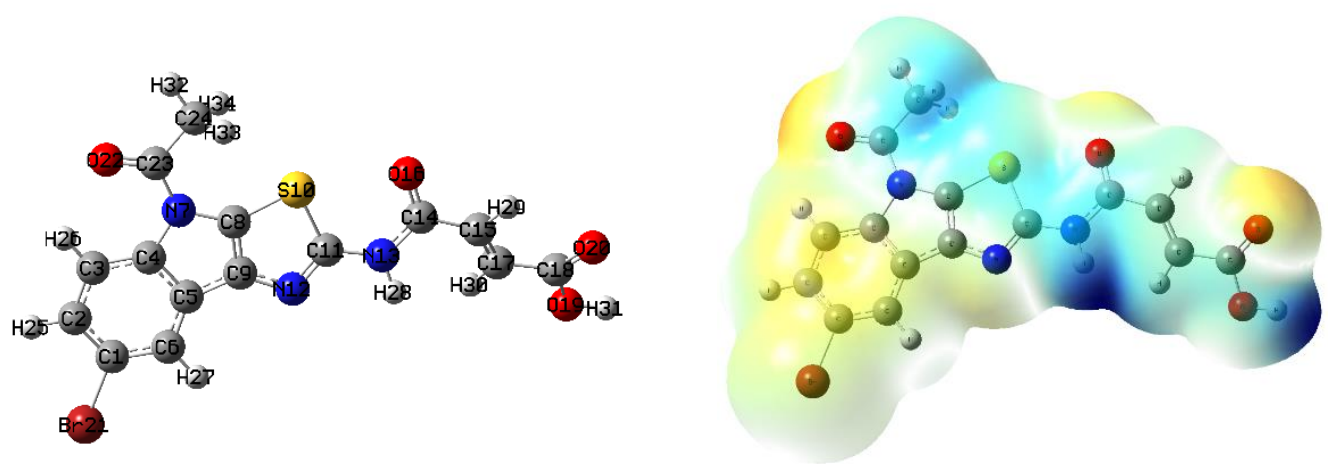

4

$-3.838 \mathrm{e}-2$

$3.838 \mathrm{e}-2$

Figure 3. The optimized structures of compounds 1-4 with their ESP maps.

Frontier molecular orbitals of compounds 1, 2, 3, and 4 are calculated by B3LYP/6$31+\mathrm{G}(\mathrm{d})$ level of theory, and corresponding results are listed in Table 1 and visualized in Figure 4. The HOMO of compounds is mainly located on aromatic rings. The LUMOs of compounds 1 and 2 are more evenly distributed over the rings, while the LUMOs of compounds 3 and 4 are located on aliphatic chains. Based on data in Table 1, The calculated $\Delta \mathrm{E}_{\mathrm{H}-\mathrm{L}}$ values for 1,2 , 3 and 4 indicate that compounds 3 and 4 with $\mathrm{C}(15)=\mathrm{C}(17)$ double bonds show lower values (3.12 and $-3.22 \mathrm{eV}$, respectively).

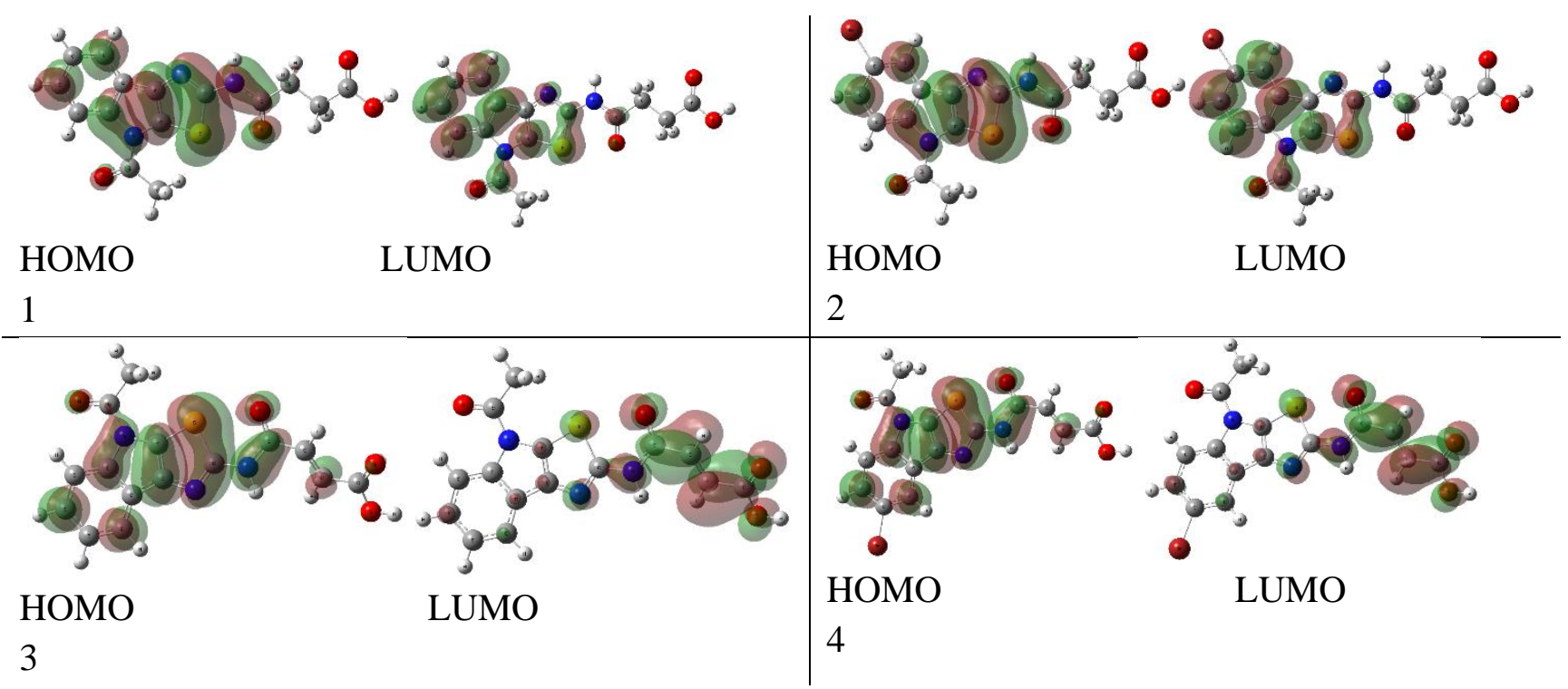

Figure 4. The HOMO and LUMO representations of compounds $1-4$ calculated by B3LYP/6-31+G(d). 
Table 1. The frontier molecular orbital energies (HOMO and LUMO), band gaps $\left(\Delta \mathrm{E}_{\mathrm{H}-\mathrm{L}}\right)$, chemical potential $(\mu)$, nucleophilicity $(\mathrm{N})$ in $\mathrm{eV}$ and the smallest calculated vibrational frequencies $\left(v_{\min }\right)$ in $\mathrm{cm}^{-1}$ for $1,2,3$ and 4 ,

\begin{tabular}{|c|c|c|c|c|c|c|c|}
\hline Compound & Еномо & ELumo & $\Delta \mathbf{E}_{\mathbf{H}-\mathrm{L}}$ & $\mathbf{N}$ & $\mu$ & $\omega$ & $V_{\min }$ \\
\hline 1 & -5.94 & -1.51 & -4.43 & 3.55 & -3.73 & 1.57 & 20.76 \\
\hline 2 & -6.07 & -1.60 & -4.47 & 3.42 & -3.83 & 1.65 & 15.13 \\
\hline 3 & -6.01 & -2.89 & -3.12 & 3.48 & -4.45 & 3.17 & 21.25 \\
\hline 4 & -6.13 & -2.91 & -3.22 & 3.35 & -4.52 & 3.18 & 25.64 \\
\hline
\end{tabular}

Valuable information can be obtained from the nucleophilicity $(\mathrm{N})$, electrophilicity $(\omega)$, chemical potential $(\mu)$ band gaps $(\Delta \mathrm{EH}-\mathrm{L})$, and their smallest calculated vibrational frequency (vmin) (see Table1).

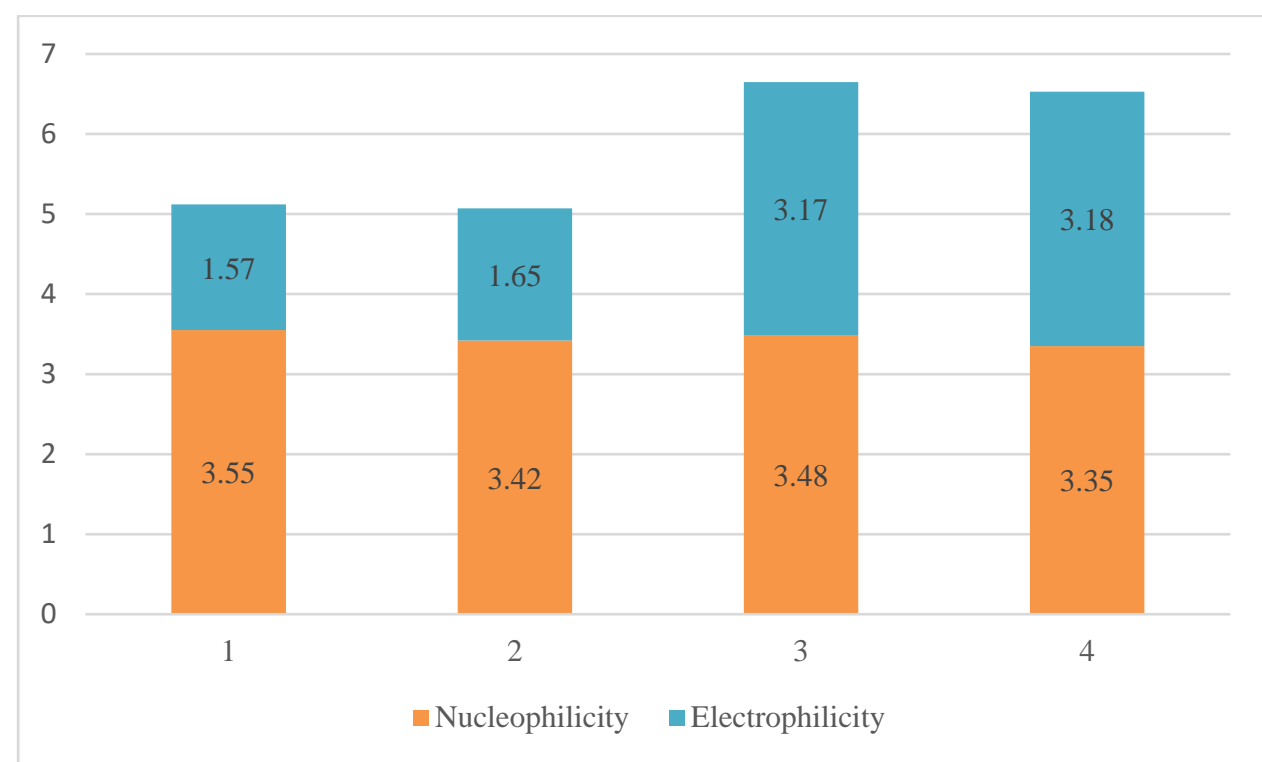

Figure 5. Comparison between nucleophilicity and electrophilicity for 1-4, at B3LYP/6-31+G(d) level of theory.

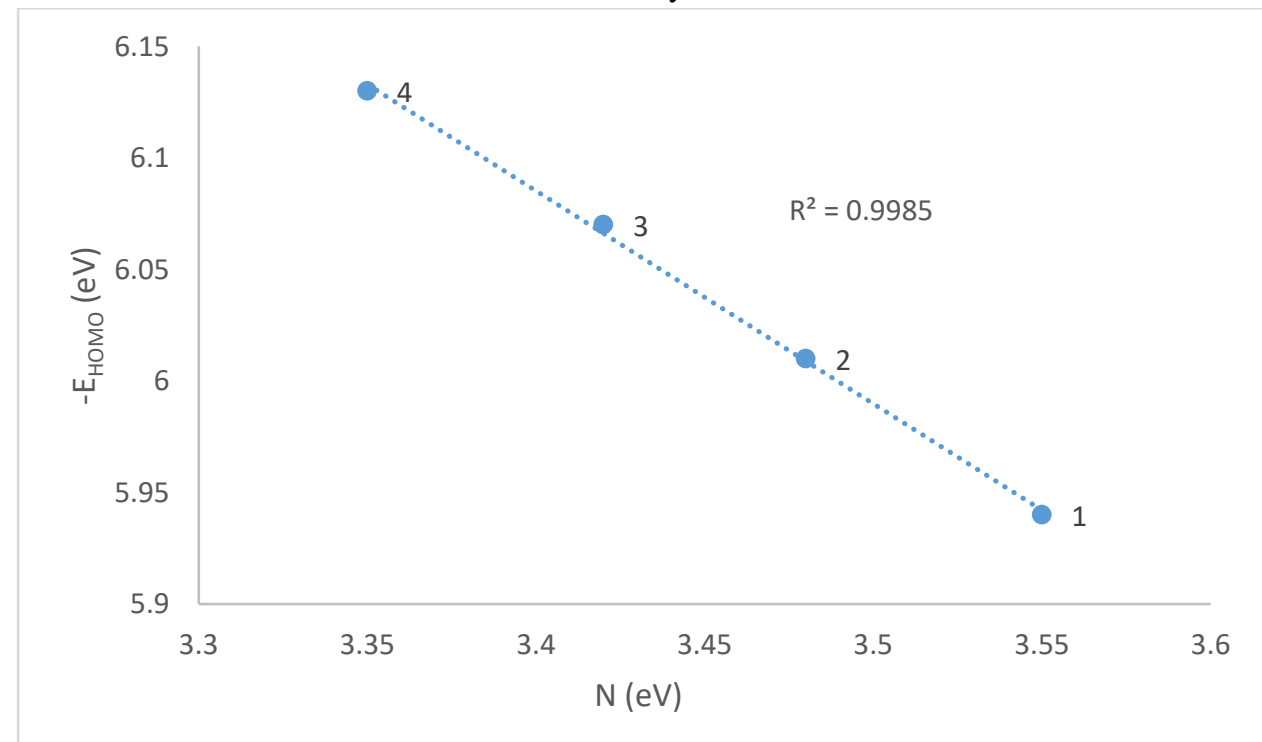

Figure. 6. Nucleophilicity plotted as a function of - $\mathrm{E}_{\mathrm{HOMO}}$ for compounds $1-4$ at B3LYP/6-31+G(d) level of theory.

Based on the results in Table 1 , the highest $\mathrm{N}$ belongs to $1(3.55 \mathrm{eV})$ while the lowest one goes to $4(3.35 \mathrm{eV})$. Nucleophilicity values are consistent with chemical potentials, HOMO energy values, and ESP maps. Therefore, by increasing the amount of $\mathrm{N}$, the $\mu$ value increases. 
The final order of $\mathrm{N}$ is $1>3>2>4$. Compounds 3 and 4 turn out as the most electrophilic structures for showing $\omega$ of 3.17 and $3.18 \mathrm{eV}$, respectively. Compound 1 represents the highest $\mathrm{N}$ and $\mu$ values while it shows the lowest $\omega$ value. The smallest calculated vibrational frequencies $\left(v \min , \mathrm{cm}^{-1}\right)$ of 1, 2, 3, and 4 can imply their stability. Every compound shows the positive force constant, which confirms the ground state. The trend of HOMO energy is the same as that of nucleophilicity and ESP map as follows: 1>3>2>4 (see Figure 5). Thus, there is a good correlation between HOMO energy and nucleophilicity values, in which by increasing the -Еномо, the value of $\mathrm{N}$ increases, as shown in Figure 6. Furthermore, the calculated Go values (a.u.) for 1, 2, 3, and 4 are tabulated in Table 2. This Table shows that compounds 1 and 3 with no $\mathrm{Br}$ atom represent lower values (-1442.66 and -1441.45 a.u., respectively).

Table 2. The calculated $\mathrm{G}^{\circ}$ (a.u.) for $1,2,3$ and 4, at B3LYP/6 31+G(d) level of theory.

\begin{tabular}{l|l|l|l|l} 
Compounds & $\mathbf{1}$ & $\mathbf{2}$ & $\mathbf{3}$ & $\mathbf{4}$ \\
\hline $\mathrm{G}^{\mathrm{o}}$ (a.u.) & -1442.66 & -4013.80 & -1441.45 & -4012.59
\end{tabular}

\subsection{NBO analysis.}

The charge distributions for optimized structures of the compounds 1,2,3, and 4calculated by the NBO (natural charge) analysis using the B3LYP/6-31+G(d) level of theory.

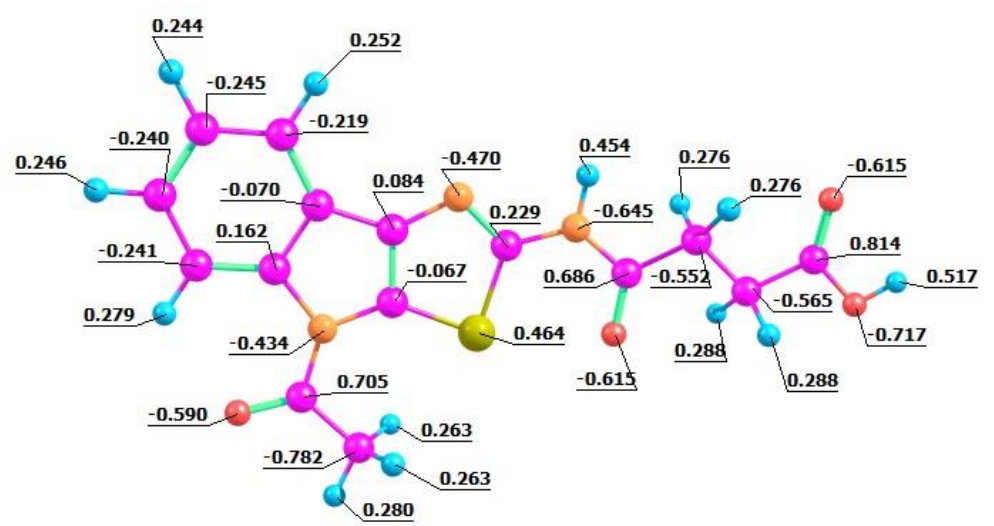

1

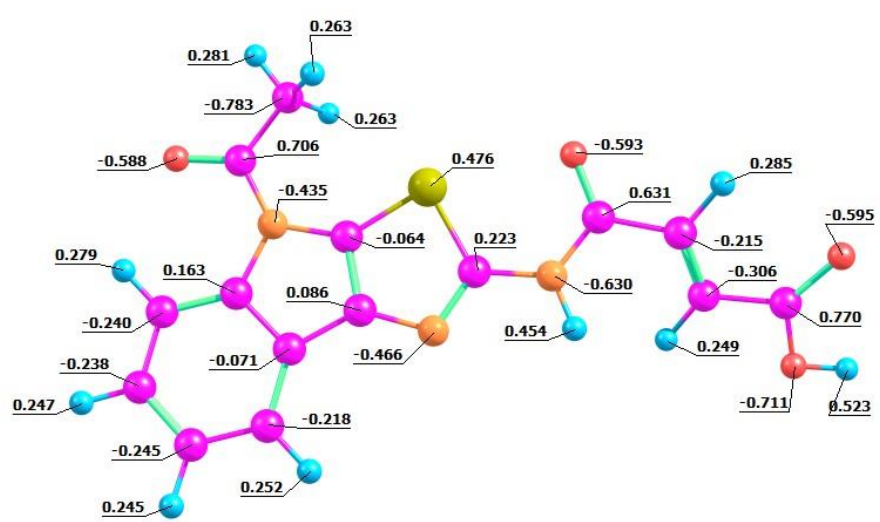

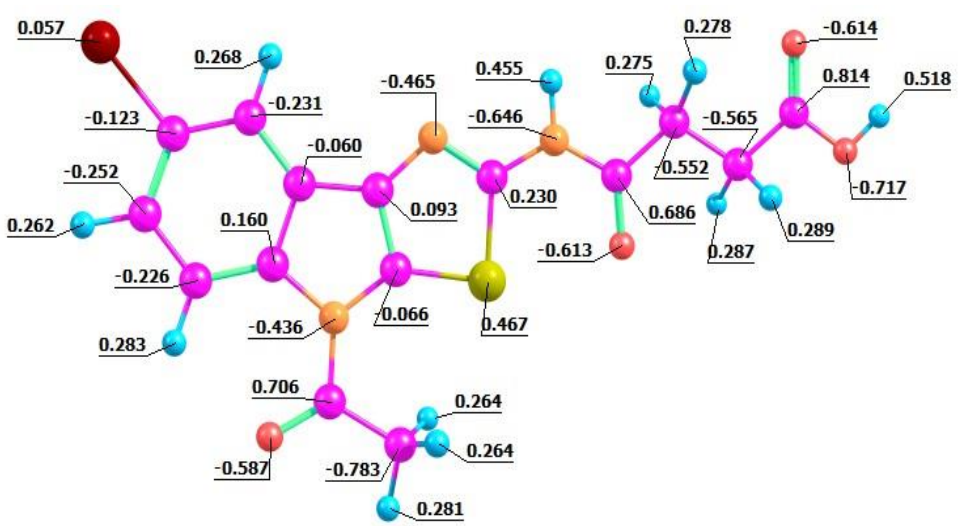

2

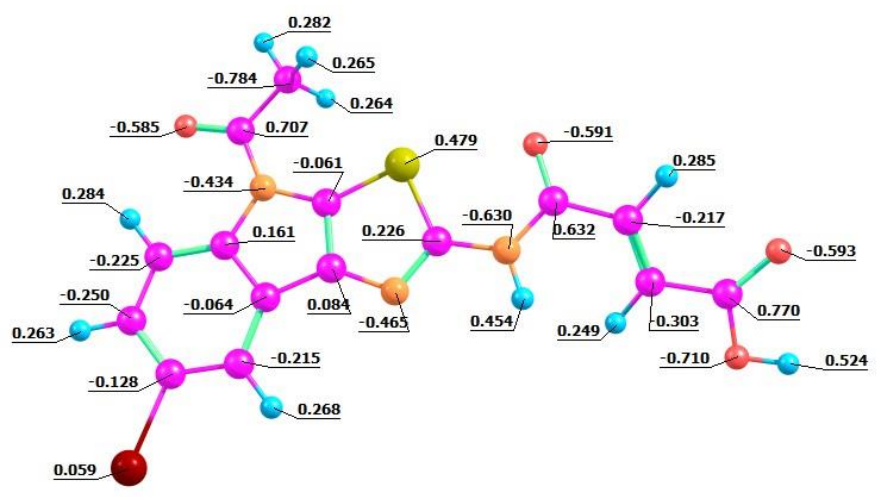

4

Figure 7. The calculated natural charges of compounds 1-4.

The results of calculated natural charges are shown in Figure 7. The total charge of the mentioned compounds is equal to zero. According to results, oxygen and sulfur atoms in all 
compounds have a negative charge, and the highest negative charge is observed for the $\mathrm{O}(19)$ atom in the $-\mathrm{OH}$ group of the carboxylic acid. In all compounds, the positive carbons are observed for the carbon atoms' attachment to the electron-withdrawing oxygen and sulfur atoms, and the other carbon atoms have a negative charge. The highest positive charge is seen for the $\mathrm{C}(18)$ atom $(0.814 \mathrm{e})$ in compounds 1 and 2 and the $\mathrm{C}(18)$ atom $(0.770)$ in compounds 3 and 4 due to the electron-withdrawing nature of the $\mathrm{O}(19)$ and $\mathrm{O}(20)$ atoms. The $\mathrm{C}(1)$ atoms in compounds 2 and 4 have a more positive charge $(-0.123 \mathrm{e}$ and $-0.128 \mathrm{e}$, respectively) compared with the $\mathrm{C}(1)$ atoms in compounds 1 and $3(-0.245 \mathrm{e})$ due to the attachment to the $\operatorname{Br}(21)$ atoms.

The analysis of interactions between the donor (Lewis-type) and acceptor (non-Lewistype) orbitals, as presented in Table 3 reveals the existence of enol-keto equilibrium in water solution. Structure 1 shows the highest second-order perturbation stabilization energy $\left(E_{2}=\right.$ $1981.82 \mathrm{kcal} / \mathrm{mol}$ ) for interaction between a lone pair of ketone's oxygen and neighboring C-H bond ( $\left.\mathrm{LPO}(21) \rightarrow \boldsymbol{\sigma}^{*} \mathrm{C}(23)-\mathrm{H}(34)\right)$. This observation is consistent with higher nucleophilicity of 1 . Structures 3 and 4 extra display interactions because of their $\mathrm{C}(15)=\mathrm{C}(17)$ double bonds, which show the resonance between $\mathrm{C}=\mathrm{C}$ and two neighboring $\mathrm{C}=\mathrm{O}$ bonds. For example, 3 exhibits $\boldsymbol{\pi}_{\mathrm{C}(15)-\mathrm{C}(17)} \rightarrow \boldsymbol{\pi}^{*} \mathrm{C}(14)-\mathrm{O}(16)$ and $\boldsymbol{\pi}_{\mathrm{C}(15)-\mathrm{C}(17)} \rightarrow \boldsymbol{\pi}^{*} \mathrm{C}(18)-\mathrm{O}(20)$ interactions with $\mathrm{E}_{2}$ of 14.24 and 18.20

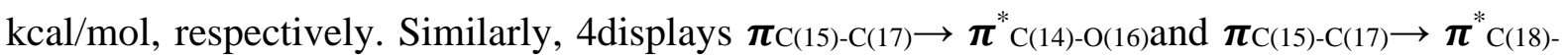
$\mathrm{o}(20)$ interactions with $\mathrm{E}_{2}$ of 14.56 and $18.09 \mathrm{kcal} / \mathrm{mol}$, respectively, which are rather similar to the values of 3 .

Table 3. Calculated second-order perturbation stabilization energies $\left(E_{2}\right)$ of selected intra-molecular interactions for 1-4 at B3LYP/6-31+G(d) level of theory.

\begin{tabular}{|c|c|c|}
\hline Compound & Donor to acceptor transitions & $\mathrm{E}_{2}(\mathrm{kcal} / \mathrm{mol})$ \\
\hline 1 & $\begin{array}{l}\mathrm{LP}_{\mathrm{O}(21)} \rightarrow \boldsymbol{\sigma}_{\mathrm{C}(23)-\mathrm{H}(34)}^{*} \\
\mathrm{LPO}(21) \rightarrow \mathrm{RY}^{*}{ }_{\mathrm{H}(28)}\end{array}$ & $\begin{array}{l}1981.82 \\
21.88\end{array}$ \\
\hline 2 & $\begin{array}{l}\mathrm{LPO}_{\mathrm{O}(22)} \rightarrow \boldsymbol{\sigma}^{*} \mathrm{C}(24)-\mathrm{H}(34) \\
\mathrm{LPO}(22) \rightarrow \mathrm{RY}^{*} \mathrm{H}(31)\end{array}$ & $\begin{array}{l}258.81 \\
89.43\end{array}$ \\
\hline 3 & $\begin{array}{l}\mathrm{LPO}(21) \rightarrow \boldsymbol{\sigma}^{*}{ }_{\mathrm{C}(23)-\mathrm{H}(32)} \\
\mathrm{LPO}(21) \rightarrow \boldsymbol{\sigma}^{*}{ }_{\mathrm{C}(23)-\mathrm{H}(33)} \\
\mathrm{LPO}(21) \rightarrow \boldsymbol{\sigma}^{*}{ }_{\mathrm{C}(23)-\mathrm{H}(34)} \\
\boldsymbol{\pi}_{\mathrm{C}(15)-\mathrm{C}(17)} \rightarrow \boldsymbol{\pi}^{*}{ }_{\mathrm{C}(14)-\mathrm{O}(16)} \\
\boldsymbol{\pi}_{\mathrm{C}(15)-\mathrm{C}(17)} \rightarrow \boldsymbol{\pi}^{*} \mathrm{C}(18)-\mathrm{O}(20)\end{array}$ & $\begin{array}{l}558.12 \\
423.87 \\
267.33 \\
14.24 \\
18.20 \\
\end{array}$ \\
\hline 4 & $\begin{array}{l}\mathrm{LPO}(22) \rightarrow \boldsymbol{\sigma}^{*} \mathrm{C}(24)-\mathrm{H}(32) \\
\mathrm{LPO}(22) \rightarrow \mathrm{RY}^{*}{ }^{\mathrm{H}(32)} \\
\mathrm{LPO}(22) \rightarrow \boldsymbol{\sigma}^{*}{ }_{\mathrm{C}(23)-\mathrm{H}(34)} \\
\boldsymbol{\pi}_{\mathrm{C}(15)-\mathrm{C}(17)} \rightarrow \boldsymbol{\pi}^{*} \mathrm{C}(14)-\mathrm{O}(16) \\
\boldsymbol{\pi}_{\mathrm{C}(15)-\mathrm{C}(17)} \rightarrow \boldsymbol{\pi}^{*} \mathrm{C}(18)-\mathrm{O}(20)\end{array}$ & $\begin{array}{l}1342.28 \\
204.35 \\
33.49 \\
14.56 \\
18.09\end{array}$ \\
\hline
\end{tabular}

\subsection{NMR Analysis.}

The theoretical ${ }^{1} \mathrm{H}$ and ${ }^{13} \mathrm{C}$ NMR chemical shift values of the compounds 1-4 were calculated using the B3LYP method with $6-31+\mathrm{G}(\mathrm{d})$ basis set using the GIAO method (Table 4 and 5) and compared with the experimental values. According to the results, in most cases, it can be seen a good agreement between calculated and experimental values.

Table 4. The theoretical ${ }^{13} \mathrm{C}$ chemical shifts of the compounds $1-4$ by using the B3LYP/6-31+G(d) method.

\begin{tabular}{l|l|l|l|l|l|l|l}
\multicolumn{2}{l|}{ Compound 1 } & \multicolumn{2}{l|}{ Compound 2 } & \multicolumn{2}{l|}{ Compound 3 } & \multicolumn{2}{l}{ Compound 4 } \\
\hline Atoms & DFT(TMS) & Atoms & DFT(TMS) & Atoms & DFT(TMS) & Atoms & DFT(TMS) \\
\hline C18 & 161.2558 & C18 & 161.2191 & C22 & 158.0252 & C23 & 158.0796 \\
\hline
\end{tabular}




\begin{tabular}{l|l|l|l|l|l|l|l}
\hline \multicolumn{2}{l}{ Compound 1 } & \multicolumn{2}{l}{ Compound 2 } & \multicolumn{2}{l}{ Compound 3 } & \multicolumn{2}{l}{ Compound 4 } \\
\hline C22 & 157.9903 & C23 & 158.0556 & C18 & 152.6639 & C18 & 152.6611 \\
\hline C14 & 156.5769 & C14 & 156.7457 & C14 & 148.7395 & C14 & 148.8082 \\
\hline C11 & 146.368 & C11 & 146.7043 & C11 & 145.9541 & C11 & 146.3152 \\
\hline C4 & 127.9998 & C4 & 126.5584 & C15 & 128.4208 & C15 & 128.2164 \\
\hline C9 & 124.2386 & C8 & 125.2782 & C4 & 128.3123 & C4 & 126.7949 \\
\hline C8 & 124.0330 & C9 & 122.9808 & C9 & 124.891 & C8 & 125.8421 \\
\hline C1 & 112.3210 & C1 & 122.9011 & C8 & 124.6379 & C9 & 123.571 \\
\hline C2 & 112.1682 & C2 & 114.5973 & C17 & 114.1973 & C1 & 123.0805 \\
\hline C5 & 111.4617 & C5 & 112.5075 & C2 & 112.5937 & C2 & 115.0494 \\
\hline C3 & 105.6992 & C6 & 108.4774 & C1 & 112.3889 & C17 & 114.4084 \\
\hline C6 & 105.6545 & C3 & 106.904 & C5 & 111.2809 & C5 & 112.3529 \\
\hline C15 & 23.8711 & C15 & 23.9677 & C3 & 105.9351 & C6 & 108.6105 \\
\hline C17 & 20.6740 & C17 & 20.6487 & C6 & 105.7942 & C3 & 107.0274 \\
\hline C23 & 17.5893 & C24 & 17.396 & C23 & 17.6494 & C24 & 17.4052
\end{tabular}

Table 5. The theoretical ${ }^{1} \mathrm{H}$ chemical shifts of the compounds 1-4 by using B3LYP/6-31+G(d) method.

\begin{tabular}{l|l|l|l|l|l|l|l}
\multicolumn{2}{l}{ Compound 1 } & \multicolumn{2}{l}{ Compound 2 } & \multicolumn{2}{l}{ Compound 3 } & \multicolumn{2}{c}{ Compound 4 } \\
\hline Atoms & DFT(TMS) & Atoms & DFT(TMS) & Atoms & DFT(TMS) & Atoms & DFT(TMS) \\
\hline H26 & 8.4721 & H26 & 9.0953 & H26 & 8.4861 & H28 & 8.4639 \\
\hline H28 & 7.8763 & H28 & 8.581 & H28 & 8.4608 & H26 & 8.4009 \\
\hline H27 & 7.7543 & H27 & 8.4788 & H27 & 7.8245 & H27 & 7.821 \\
\hline H24 & 7.389 & H25 & 7.9923 & H24 & 7.4087 & H25 & 7.3114 \\
\hline H25 & 7.3541 & H33 & 7.1106 & H25 & 7.3823 & H29 & 7.0893 \\
\hline H33 & 6.3952 & H31 & 3.5057 & H29 & 7.1002 & H31 & 6.6797 \\
\hline H31 & 2.7617 & H30 & 3.4642 & H31 & 6.6691 & H30 & 6.3764 \\
\hline H32 & 2.7597 & H32 & 3.4531 & H30 & 6.3717 & H33 & 2.5523 \\
\hline H29 & 2.7179 & H29 & 3.407 & H33 & 2.5662 & H34 & 2.5387 \\
\hline H30 & 2.7177 & H36 & 3.2412 & H34 & 2.558 & H32 & 2.2357 \\
\hline H36 & 2.5421 & H35 & 3.2411 & H32 & 2.2286 & & \\
\hline H35 & 2.5419 & H34 & 2.9255 & & & & \\
\hline H34 & 2.2128 & & & & & &
\end{tabular}

Compound 1. The peaks around $20 \mathrm{ppm}$ of ${ }^{13} \mathrm{C}$ NMR are related to the most shielded carbons $\left(\mathrm{C} 23\left(-\mathrm{CH}_{3}\right), \mathrm{C} 17\left(-\mathrm{CH}_{2}\right)\right.$, and $\left.\mathrm{C} 15\left(-\mathrm{CH}_{2}\right)\right)$, which are mentioned with a red circle (Table 4). Most deshielded carbons are related to $\mathrm{C} 18, \mathrm{C} 22$, and $\mathrm{C} 14$ which belong to carboxylic acid, ketone, and amide groups, respectively (around $160 \mathrm{ppm}$ ).

The reason for the shielding of hydrogens 29-32 and 34-36 is related to the enol-keto equilibrium in the aqueous medium. Due to the enol-keto equilibrium, an unbound electron pair of oxygen enters hydrogen and magnetically shields it (Table 5). The highest shielding rate is related to hydrogen 34, which means that in the enol-keto equilibrium in the aqueous medium, hydrogen 34 plays the largest role. But hydrogens 29 and 30 are more shielded due to their proximity to the lethal amide group. Also, hydrogens 31 and 32 are closer to the more lethal carboxylic acid group, showing a higher degree of de-shielding. Benzene ring hydrogens have also appeared in the range of 6-9 ppm. These observations fit well with the experimental spectrum (Sec. 2.4), and in some cases, differences are seen. Like the hydrogen carboxylic acid group that appeared in the main spectrum in the range of 12 to $13 \mathrm{ppm}$ but in the calculated spectrum, it can be seen at $6.39 \mathrm{ppm}$ that it can be due to hydrogen bonding and solvent effects. Also, hydrogen amide is observed in the experimental spectrum in the range of 3-4 ppm and in the calculated spectrum in the range of 7.5-8 ppm.

Compound 2. The ${ }^{13} \mathrm{C}$ NMR spectrum of compound 2 shows a different pattern in the range of 100-160 ppm than in compound 1 due to differences in the hydrogen topicality of the benzene ring. Here, too, the most shielded carbons are numbers 24, 17, and 15 (Table 4). 
The ${ }^{1} \mathrm{H}$ NMR spectra of compound 2 are similar to compound 1 and show a similar pattern for deshielded hydrogens. Hydrogens 25-28 are the most shielded hydrogens. Due to the replacement of bromine atoms with hydrogen 24 in compound 1, a slightly different spectrum pattern is observed in the aromatic hydrogen region, which reduces degeneration. Here, too, the most shielded hydrogen is number 34 . The hydrogen of the amide group appears in the region of $7.11 \mathrm{ppm}$, while for compound 1, about $6.40 \mathrm{ppm}$ is observed. In general, the peaks of compound 2 have shifted to more ppm (Table 5). In the experimental spectrum of compound 2, aromatic hydrogens appeared in the range of 7-8 ppm (Sec 4.2), but in the calculated spectrum in the range of 8-9 ppm.

Compound 3. The ${ }^{13} \mathrm{C}$ NMR spectrum of compound 3 is different from the spectra of compounds 1 and 2 due to the dual bonding between carbons 15 and 17. The most shielded carbon is carbon number 23. The most deshielded carbons are carbons 22, 18, 14, and 11, related to ketone, carboxylic acid, amide and attached to two nitrogen atoms (140-160 ppm), respectively (Table 4). The interesting thing about compound 3 is that the most shielded hydrogens are 32-34, which are attached to the carbon adjacent to the ketone group and appear in the 2-3 ppm region. The double-bonded hydrogens 29 and 30 are more deshielded than compounds 1 and 2. Hydrogens 28 and 31 appeared at 8.46 and 6.67 ppm, respectively (Table 5), differing from the experimental spectrum ( $\operatorname{Sec} 2.4)$.

Compound 4. The ${ }^{13} \mathrm{C}$ NMR spectrum of compound 4 is similar to that of compound 3. The difference is that the most shielded carbon is carbon 24 , the methyl carbon attached to the ketone. Also, in the range of $100-160 \mathrm{ppm}$ due to the presence of bromine atoms, more complexity is observed in the pattern of the compound 4 spectrum (Table 4). In the regions of 128.22 and 114.41 ppm, hydrogens No. 15 and 17 of the double bond appear, respectively. The most deshielded carbon is number 23, which, like compound 3, is ketone carbon.

As in Compound3, for Compound4, the most shielded hydrogens are in the 2-3 ppm range and belong to hydrogens 32-34 (Table 5). The main difference between the ${ }^{1} \mathrm{H}$ NMR spectra of compound 4 and compound 3 is in the range of 6-9 ppm, which shows a different pattern due to the presence of bromine substitution on the benzene ring.

\subsection{Vibrational frequencies.}

The theoretical IR spectra of the optimized compounds 1-4 were calculated using the B3LYP/6-31+G(d) level of energy. The vibrational frequencies assignments were made using the GaussView 05 program. The theoretical frequencies computed by the DFT method are commonly higher than the corresponding experimental data due to the approximation of the electron correlation, basis set deficiencies, and anharmonicity effects [49].

Compound 1 . The analysis of compound 1 shows that the stretching vibrations of 3581 and $3671 \mathrm{~cm}^{-1}$ are related to N-H amide and O-H carboxylic acid, respectively. At $1775 \mathrm{~cm}^{-1}$ the stretching vibrations of the carbonyl carboxylic acid group are seen. At 1725 and $1718 \mathrm{~cm}^{-}$

${ }^{1}$ the stretching vibrations of the carbonyl groups corresponding to the ketone group and the amide group appeared (Table 6). The presence of resonance in the amide group has reduced its frequency compared to ketones. The obtained pattern is similar to the main spectrum, with a slight shift towards higher frequencies, especially for ketone groups.

Compound 2. For compound 2, a slight increase in the stretching vibrations of the carbonyl groups of the ketone group and the amide group is observed (1730 and $\left.1719 \mathrm{~cm}^{-1}\right)$. The stretching vibration associated with benzene ring hydrogens almost disappears in this 
compound and is not seen (Table 6). For compound 2, peaks appear at higher stretching vibrations than for its experimental IR spectrum.

Compound 3. At $3214 \mathrm{~cm}^{-1}$, stretching peaks corresponding to two hydrogen double bonds are observed. At 1719 and $1670 \mathrm{~cm}^{-1}$, the symmetric and asymmetric stretching vibration speaks of the amide group, and the unsaturated $\alpha$ and $\beta$ ketone groups are observed, respectively, which do not exist for compounds 1 and 2 due to the absence of a carbon-carbon double bond. In the experimental spectrum of compound 3, many peaks are seen in the range of $3000 \mathrm{~cm}^{-1}$, which appear in the calculated spectrum in the range of $3500 \mathrm{~cm}^{-1}$ (Table 6). In general, in the calculated spectrum compared to the experimental, a slight shift to higher frequencies is also seen.

Compound 4. At $3214 \mathrm{~cm}^{-1}$, stretching peaks corresponding to two hydrogen double bonds are observed. As in compound 3, at 1719 and $1670 \mathrm{~cm}^{-1}$ (Table 6), the symmetric and asymmetric stretching vibration peaks of the amide group and the unsaturated $\alpha$ and $\beta$ ketone groups, respectively, which do not exist for compounds 1 and 2 due to the absence of a carboncarbon double bond. In 1732 and $1762 \mathrm{~cm}^{-1}$, tensile peaks of ketone groups and unsaturated $\alpha$ and $\beta$ acid groups are also observed. At 3590 and $3671 \mathrm{~cm}^{-1}$, the stretching vibration for the $\mathrm{N}$ $\mathrm{H}$ amide and acidic $\mathrm{O}-\mathrm{H}$, respectively, appear.

Table 6. Calculated vibrational frequencies and their intensity of the compound 1-4 by using the B3LYP/6$31+\mathrm{G}(\mathrm{d})$ method.

\begin{tabular}{|c|c|c|c|c|c|c|c|}
\hline \multicolumn{2}{|c|}{ Compound 1} & \multicolumn{2}{|c|}{ Compound 2} & \multicolumn{2}{|c|}{ Compound 3} & \multicolumn{2}{|c|}{ Compound 4} \\
\hline$v_{\text {cal. }}\left(\mathrm{cm}^{-1}\right)$ & IR intensity & $v_{\text {cal. }}\left(\mathrm{cm}^{-1}\right)$ & IR intensity & $v_{\text {cal. }}\left(\mathrm{cm}^{-1}\right)$ & IR intensity & $v_{\text {cal. }}\left(\mathrm{cm}^{-1}\right)$ & IR intensity \\
\hline 28 & 599.53 & 122 & 12.75 & 30 & 594.72 & 34 & 393.64 \\
\hline 39 & 537.18 & 286 & 14.53 & 52 & 315.63 & 36 & 286.28 \\
\hline 61 & 346.90 & 365 & 17.03 & 665 & 373.18 & 55 & 323.42 \\
\hline 97 & 785.90 & 482 & 43.00 & 763 & 447.48 & 80 & 171.14 \\
\hline 117 & 318.38 & 521 & 51.31 & 981 & 248.40 & 115 & 406.95 \\
\hline 192 & 343.12 & 552 & 76.06 & 1017 & 149.91 & 121 & 195.94 \\
\hline 242 & 282.49 & 615 & 54.19 & 1149 & 2326.89 & 146 & 276.55 \\
\hline 280 & 152.46 & 640 & 150.72 & 1164 & 129.96 & 178 & 283.19 \\
\hline 363 & 163.48 & 721 & 80.61 & 1213 & 314.24 & 237 & 162.53 \\
\hline 549 & 598.67 & 761 & 70.27 & 1240 & 16.82 & 351 & 270.81 \\
\hline 583 & 210.73 & 842 & 48.29 & 1280 & 27.87 & 401 & 225.24 \\
\hline 608 & 352.66 & 901 & 6.9213 & 1295 & 1107.65 & 543 & 563.08 \\
\hline 610 & 378.40 & 921 & 20.75 & 1306 & 547.07 & 570 & 481.00 \\
\hline 644 & 888.295 & 927 & 25.81 & 1319 & 1129.97 & 609 & 451.90 \\
\hline 667 & 69.10 & 981 & 112.71 & 1320 & 1127.77 & 621 & 464.11 \\
\hline 694 & 190.41 & 996 & 33.04 & 1352 & 633.04 & 717 & 314.06 \\
\hline 762 & 561.68 & 1037 & 14.84 & 1383 & 1199.39 & 843 & 244.56 \\
\hline 979 & 211.44 & 1066 & 9.48 & 1388 & 319.40 & 918 & 84.21 \\
\hline 996 & 126.58 & 1081 & 22.95 & 1418 & 317.39 & 958 & 241.00 \\
\hline 1147 & 2086.27 & 1086 & 37.31 & 1454 & 305.73 & 983 & 499.16 \\
\hline 1164 & 128.36 & 1138 & 54.96 & 1466 & 270.96 & 1148 & 2145.69 \\
\hline 1214 & 280.84 & 1145 & 533.21 & 1488 & 71.57 & 1218 & 368.31 \\
\hline 1277 & 1065.83 & 1276 & 340.14 & 1495 & 316.39 & 1318 & 2146.12 \\
\hline 1299 & 201.44 & 1300 & 149.06 & 1514 & 59.90 & 1339 & 483.53 \\
\hline 1306 & 333.41 & 1319 & 682.37 & 1531 & 157.86 & 1381 & 1135.14 \\
\hline 1320 & 1853.55 & 1384 & 272.09 & 1584 & 2046.93 & 1465 & 510.03 \\
\hline 1351 & 844.97 & 1719 & 346.81 & 1670 & 874.13 & 1496 & 447.52 \\
\hline 1372 & 583.32 & 1730 & 721.36 & 1719 & 817.57 & 1585 & 2123.13 \\
\hline 1388 & 573.03 & 1774 & 473.14 & 1728 & 1544.91 & 1643 & 308.55 \\
\hline 1583 & 2472.11 & 3065 & 6.71 & 1762 & 1223.84 & 1670 & 819.39 \\
\hline 1718 & 733.02 & 3078 & 15.65 & 3174 & 13.75 & 1719 & 684.08 \\
\hline 1725 & 1789.96 & 3118 & 7.48 & 3203 & 30.46 & 1732 & 1562.60 \\
\hline
\end{tabular}




\begin{tabular}{l|l|l|l|l|l|l|l}
\hline \multicolumn{2}{l}{ Compound 1 } & \multicolumn{2}{l}{ Compound 2 } & \multicolumn{2}{l}{ Compound 3 } & \multicolumn{2}{l}{ Compound 4 } \\
\hline 1775 & 1069.02 & 3174 & 10.94 & 3214 & 45.61 & 1762 & 1223.53 \\
\hline 3581 & 119.23 & 3576 & 110.05 & 3588 & 105.26 & 3590 & 103.18 \\
\hline 3671 & 116.08 & 3669 & 107.42 & 3672 & 187.11 & 3671 & 185.54
\end{tabular}

\subsection{Pharmacokinetic properties.}

Protease and kinase inhibition activity by natural and synthetic inhibitors prevents the proliferation of tumor cells and thus presents a promising strategy for anticancer therapy [5052]. The results of pharmacokinetic properties are presented in Table 7. The Lipinski rule of five estimated drug-likeness includes four simple physicochemical parameter ranges (MWT $\leq$ 500, $\log \mathrm{P} \leq 5, \mathrm{H}$-bond donors $\leq 5, \mathrm{H}$-bond acceptors $\leq 10$ ) accompanied with $90 \%$ of orally active drugs that have passed phase II clinical triles. The Milog $\mathrm{P}$ values of these compounds are observed to be $<5$ (2.08-2.89 for compounds 1 to 4$)$ showed their good permeability across the cell membrane. These compounds were observed to have TPSA will be below $160 \AA 2$, molecular weight is less than 500, No. of hydrogen bond donors $\leq 5$, No. of hydrogen acceptor $\leq 10$, n-violations equal to zero, number of rotatable flexible bonds $>5$. The bioactivity score profile of all studied structures is presented in Table 8. According to Table 8, the bioactivity scores for organic molecules can be described as active (when the bioactivity score is $>0$ ), moderately active (when the bioactivity score lies between -5.0 and 0.0 ), and inactive (when the bioactivity score $<-5.0$ ). This shows that each compound can be considered moderately bioactive as a Protease inhibitor, besides acting as a ligand for GPCR and as an Enzyme inhibitor.

Table 7. Pharmacokinetic properties of the compounds $1-4 .^{*}$

\begin{tabular}{l|l|l|l|l|l|l|l|l|l} 
Compound & milogP & TPSA & natoms & MW & nON & nOHNH & n-violations & nrotb & $\mathbf{V}_{\mathbf{m}}$ \\
\hline 1 & 2.10 & 101.29 & 23 & 331.35 & 7 & 2 & 0 & 4 & 271.49 \\
\hline 2 & 2.89 & 101.29 & 24 & 410.25 & 7 & 2 & 0 & 4 & 289.37 \\
\hline 3 & 2.08 & 101.29 & 23 & 329.34 & 7 & 2 & 0 & 3 & 265.30 \\
\hline 4 & 2.87 & 101.29 & 24 & 408.23 & 7 & 2 & 0 & 3 & 283.18
\end{tabular}

*miLogP (the octanol/water partition coefficient), TPSA (the molecular polar surface area), natoms (the number of atoms of the molecule), nON (the number of hydrogen bond acceptors), nOHNH (the number of hydrogen bond donors), n-violations (the number of violations of the Ro5), nrotb (the number of rotatable bonds), $V_{m}$ (the molecular volume) and MW (the molecular weight).

Table 8. Bioactivity scores against different drug targets of the compounds 1-4.

\begin{tabular}{l|l|l|l|l|l|l} 
Compound & GPCR ligand & $\begin{array}{l}\text { Ion channel } \\
\text { modulator }\end{array}$ & $\begin{array}{l}\text { Kinase } \\
\text { inhibitor }\end{array}$ & $\begin{array}{l}\text { Nuclear receptor } \\
\text { ligand }\end{array}$ & $\begin{array}{l}\text { Protease } \\
\text { inhibitor }\end{array}$ & $\begin{array}{l}\text { Enzyme } \\
\text { inhibitor }\end{array}$ \\
\hline 1 & -0.21 & -0.59 & -0.17 & -0.59 & -0.35 & -0.10 \\
\hline 2 & -0.34 & -0.69 & -0.21 & -0.72 & -0.47 & -0.19 \\
\hline 3 & -0.24 & -0.61 & -0.11 & -0.50 & -0.37 & -0.12 \\
\hline 4 & -0.37 & -0.70 & -0.15 & -0.64 & -0.49 & -0.21
\end{tabular}

\section{Conclusions}

Four new derivatives of butanoic Acid: 4-((4-acetyl-4H-thiazolo[5,4-b]indol-2yl)amino)-4-oxobutanoic acid (1), 4-((4-acetyl-7-bromo-4H-thiazolo[5,4-b]indol-2-yl)amino)4-oxobutanoic acid (2), (E)-4-((4-acetyl-4H-thiazolo[5,4-b]indol-2-yl)amino)-4-oxobut-2enoic acid (3) and (E)-4-((4-acetyl-7-bromo-4H-thiazolo[5,4-b]indol-2-yl)amino)-4-oxobut-2enoic acid (4) was synthesized from 2-amino-4-acetyl-7-bromothiazolo[5,4-b]indole and succinic anhydride (1 and 2) and 2-amino-4-acetylthiazolo[5,4-b]indole and maleic anhydride (3 and 4). The structures were characterized by FT-IR, NMR spectroscopic techniques. The 
electronic and geometrical parameters of title molecules were computed by using DFT/ B3LYP/6-31+G(d) in the ground state. The observed and computed values were compared. The results show the trend of HOMO energy is the same as nucleophilicity and ESP map: $1>3>2>4$. By increasing the energy of HOMO, $N$ increases. Moreover, the NBO analysis reveals the existence of enol-keto equilibrium in water solution. Structure 1 shows the highest second-order perturbation stabilization energy $\left(\mathrm{E}_{2}=1981.82 \mathrm{kcal} / \mathrm{mol}\right)$ for interaction between a lone pair of ketone's oxygen and neighboring $\mathrm{C}-\mathrm{H}$ bond. Structures 3 and 4 extra display interactions because of their $\mathrm{C}(15)=\mathrm{C}(17)$ double bonds, which show the resonance between $\mathrm{C}=\mathrm{C}$ and two neighboring $\mathrm{C}=\mathrm{O}$ bonds. The theoretical FT-IR, ${ }^{1} \mathrm{H}$, and ${ }^{13} \mathrm{C}$ NMR chemical shift values of the compounds 1-4 were calculated by the B3LYP/6-31+G(d) method is in good agreement with the experimental results. Milog $\mathrm{P}$ values of these compounds showed their good permeability across the cell membrane. All titled compounds can be considered moderately bioactive as a Protease inhibitor, besides acting as a ligand for GPCR and as an Enzyme inhibitor.

\section{Funding}

This research received no external funding.

\section{Acknowledgments}

The authors acknowledged the technical support provided by prof. Siyamak Shahab at Belarusian State University.

\section{Conflicts of Interest}

The authors declare no conflict of interest.

\section{References}

1. Pattayil, L.; Balakrishnan-Saraswathi, H.T. In vitro evaluation of apoptotic induction of butyric acid derivatives in colorectal carcinoma cells. Anticancer Research 2020, 39, 3795-3801, https://doi.org/10.21873/anticanres.13528.

2. Miller. A.A.; Kurschel, E.; Osieka, R.; Schmidt, C.G. Clinical pharmacology of sodium butyrate in patients with acute leukemia. European Journal of Cancer Research \& Clinical Oncology 1987, 23, 1283-1287, https://doi.org/10.1016/0277-5379(87)90109-X.

3. Novogrodsky, A.; Dvir, A.; Ravid, A.; Shkolnik, T.; Stenzel, K.H.; Rubin, A.L.; Zaizov, R. Effect of polar organic compounds on leukemic cells. Butyrate-induced partial remission of acute myelogenous leukemia in a child. Cancer 1983, 51, 9-14, https://doi.org/10.1002/1097-0142(19830101)51:1<9::AIDCNCR2820510104>3.0.CO;2-4.

4. Ferrante, R.J.; Kubilus, J.K.; Lee, J.; Ryu, H.; Beesen, A.; Zucker, B.; Smith, K.; Kowall, N.W.; Ratan, R.R.; Luthi-Carter, R. Histone deacetylase inhibition by sodium butyrate chemotherapy ameliorates the neurodegenerative phenotype in Huntington's disease mice. Journal of Neuroscience 2003, 23, 9418-9427, https://doi.org/10.1523/JNEUROSCI.23-28-09418.2003.

5. Imai, K.; Okamoto, T.; Ochiai, K. Involvement of Sp1 in butyric acid-induced HIV-1 gene expression. Cellular Physiology and Biochemistry 2015, 37, 853-865, https://doi.org/10.1159/000430213.

6. Entin-Meer, M.; Rephaeli, A.; Yang, X.; Nudelman, A.; VandenBerg, S.R.; Haas-Kogan, D.A. Butyric acid prodrugs are histone deacetylase inhibitors that show antineoplastic activity and radiosensitizing capacity in the treatment of malignant gliomas. Molecular Cancer Therapeutics 2005, 4, 1952-1961, https://doi.org/10.1158/1535-7163.MCT-05-0087. 
7. Zhang, Y.; Zhou, L.; Bao, Y.L.; Wu, Y.; Yu, C.L.; Huang, Y.X., Sun, Y., Zheng, L.H., Li, Y.X. Butyrate induces cell apoptosis through activation of JNK MAP kinase pathway in human colon cancer RKO cells. Chemico-Biological Interactions 2010, 185, 174-181, https://doi.org/10.1016/j.cbi.2010.03.035.

8. Blouin, J.M.; Penot, G.; Collinet, M.; Nacfer, M.; Forest, C.; Laurent-Puig, P.; Coumoul, X.; Barouki, R.; Benelli, C.; Bortoli, S. Butyrate elicits a metabolic switch in human colon cancer cells by targeting the pyruvate dehydrogenase complex. International Journal of Cancer 2011, 128, 2591-2601, https://doi.org/10.1002/ijc.25599.

9. Daniel, P.; Brazier, M.; Cerutti, I.; Pieri, F.; Tardivel, I.; Desmet, G.; Baillet, J.; Chany, C. Pharmacokinetic study of butyric acid administered in vivo as sodium and arginine butyrate salts. Clinica Chimica Acta 1989, 181, 255-263, https://doi.org/10.1016/0009-8981(89)90231-3.

10. Kerru, N.; Gummidi, L.; Bhaskaruni, S.V.H.S.; Maddila, S.N.; Singh, P.; Jonnalagadda, S.B. A comparison between observed and DFT calculations on structure of 5-(4-chlorophenyl)-2-amino-1, 3, 4-thiadiazole. Scientific Reports 2019, 9, 1-17, https://doi.org/10.1038/s41598-019-55793-5.

11. Kauser, S.; Shaikh, J.; Sannaikar, M.S.; Kumbar, M.N.; Bayannavar, P.K.; Kamble, R.R.; S.R. Inamdar, S.D. Joshi Microwave-Expedited Green Synthesis, Photophysical, Computational Studies of Coumarin-3-ylthiazol-3-yl-1,2,4-triazolin-3-ones and Their Anticancer Activity. Chemistry Select 2018, 3, 4448- 4462, https://doi.org/10.1002/slct.201702596.

12. Flores, M.C.; Marquez, E.A.; Mora, J.R.; Molecular modeling studies of Bromo pyrrole alkaloids as potential antimalarial compounds: a DFT approach. Medicinal Chemistry Research 2018, 27, 844-856, https://doi.org/10.1007/s00044-017-2107-3.

13. Kerzare, D.; Chikhale, R.; Bansode, R.; Amnerkar, N., Karodia, N.; Paradkar, A.; Khedekar, P. Design, Synthesis, Pharmacological Evaluation and Molecular Docking Studies of Substituted Oxadiazolyl-2Oxoindolinylidene Propane Hydrazide Derivatives. Journal of the Brazilian Chemical Society 2016, 27, 1998-2010, https://doi.org/10.5935/0103-5053.20160090.

14. El-Mansy, M.A.; Osman, O.; Mahmoud, A.A.; Elhaes, H.; Gawad, A.E.A.; Ibrahim, M.A. Computational Notes on the Chemical Stability of Flutamide. Lett. Appl. NanoBioScience 2020, 9, 1147-1155, https://nanobioletters.com/wp-content/uploads/2020/06/2284680893.11471155.pdf.

15. Schmidt, A.; Lindner, A.S.; Casado, J.; Ramirez, F.J. Vibrational spectra and quantum chemical calculations of uracilyl-pyridinium mesomeric betaine. Journal of Raman Spectroscopy 2007, 38, 1500-1509, https://doi.org/10.1002/jrs.1803.

16. Amalanathan, M.; Suresh, D.M.; Hubert, J.I.; Bena, J.V.; Sebastian, S.; Ayyapan, S. FT-IR and FT-Raman Spectral Investigation and DFT Computations of Pharmaceutical Important Molecule: Ethyl 2-(4-Benzoyl2,5Dimethylphenoxy) Acetate. Pharmaceutica Analytica Acta 2016, 7, 1-8, https://doi.org/10.4172/21532435.1000457.

17. Tighadouini, S.; Benabbes, R.; Tillard, M.; Eddike, D.; Haboubi, K.; Karrouchi, K.; Radi, S. Synthesis, crystal structure, DFT studies and biological activity of (Z)-3-(3-bromophenyl)-1-(1, 5-dimethyl-1 H-pyrazol-3-yl)3-hydroxyprop-2-en-1-one. Chemistry Central Journal 2018, 12, 1-11, doi.org/10.1186/s13065-018-0492-4.

18. Adejumo, T.T.; Tzouras, N.V.; Zorba, L.P.; Radanović, D.; Pevec, A.; Grubišić, S.; Mitić, D.; Anđelković, K.K.; Vougioukalakis, G.C.; Cobeljic, B. Synthesis, Characterization, Catalytic Activity, and DFT Calculations of $\mathrm{Zn}$ (II) Hydrazone Complexes. Molecules 2020, 25, 4043, https://doi.org/10.3390/molecules25184043.

19. Iwan, A.; Schab-Balcerzak, E.; Grucela-Zajac, M.; Skorka, L. Structural characterization, absorption and photoluminescence study of symmetrical azomethines with long aliphatic chains. Journal of Molecular Structure 2014, 1058, 130-135, https://doi.org/10.1016/j.molstruc.2013.10.067.

20. Almodarresiyeh, H.; Shahab, S.; V. Zelenkovsky, V.; Agabekov. Electronic structure and absorption spectra of sodium 2-hydroxy-5-(\{2-methoxy-4[(4-sulfophenyl)diazenyl]phenyl\} diazenyl)benzoate. Journal of Applied Spectroscopy 2014, 81, 161-163, https://doi.org/10.1007/s10812-014-9903-z.

21. Almodarresiyeh, H.; Shahab, S.; Zelenkovsky, V.; Ariko, N., Filippovich, L.; Agabekov, V. Calculation of UV, IR, and NMR spectra of diethyl 2,2'-[(1,1'-Biphenyl)-4,4'-diylbis(azanediyl)] diacetate. Journal of Applied Spectroscopy 2014, 81, 31-36, https://doi.org/10.1007/s10812-014-9882-0.

22. Shahab, S.; Filippovich, L.; Kumar, R.; Darroudi, M.; Yousefzadeh Borzehandani, M., Gomar, M. Photochromic properties of the molecule Azure A chloride in polyvinyl alcohol matrix. Journal of Molecular Structure 2015, 1101, 109-115, https://doi.org/10.1016/j.molstruc.2015.08.007. 
23. Shahab, S.; Alhosseini Almodarresiyeh, H.; Kumar, R.; Darroudi, M. A study of molecular structure, UV, IR, and 1H NMR spectra of a new dichroic dye on the basis of quinoline derivative. Journal of Molecular Structure 2015, 1088, 105-110, https://doi.org/10.1016/j.molstruc.2015.01.047.

24. Akalin, E.; Akyuz, S.; Vibrational structure of free and hydrogen bonded complexes of isoniazid: FT-IR, FTRaman and DFT study. Journal of Molecular Structure 2007, 834, 492-497, https://doi.org/10.1016/j.molstruc.2006.12.056.

25. Ramasamy, R.; Krishnakumar, V. Density functional and experimental studies on the FT-IR and FT-Raman spectra and structure of 2,6-diamino purine and 6-methoxy purine. Spectrochimica Acta Part A: Molecular and Biomolecular Spectroscopy. 2008, 69, 8-17. https://doi.org/10.1016/j.saa.2007.02.020.

26. Shahab, S.; Sheikhi, M.; Filippovich, L.; Dikusar, E.; Yahyaei, H.; Kumar, R.; Khaleghian, M. Design of geometry, synthesis, spectroscopic (FT-IR, UV/Vis, excited state, polarization) and anisotropy (thermal conductivity and electrical) properties of new synthesized derivatives of (E,E)-azomethines in colored stretched poly (vinyl alcohol) matrix. Journal of Molecular Structure 2018, 1157, 536-550, https://doi.org/10.1016/j.molstruc.2017.12.094.

27. Aarjane, M.; Slassi, S.; Ghaleb, A.; Amine, A. Synthesis, spectroscopic characterization (FT-IR, NMR) and DFT computational studies of new isoxazoline derived from acridone. Journal of Molecular Structure 2021, 1231, 129921, https://doi.org/10.1016/j.molstruc.2021.129921.

28. Chortani, S.; Horchani, M.; Znati, M.; Issaoui, N.; Jannet, H.B.; Romdhane, A. Design and synthesis of new benzopyrimidinone derivatives: $\alpha$-amylase inhibitory activity, molecular docking and DFT studies. Journal of Molecular Structure 2021, 1230, 129920, https://doi.org/10.1016/j.molstruc.2021.129920.

29. Saranya, K.; Murugavel, S.; Synthesis of novel thiophene fused pyrazoline-thiocyanatoethanone derivative: Spectral, DFT, pharmacological, docking and in vitro antibacterial studies. Journal of Molecular Structure 2021, 1229, 129487. https://doi.org/10.1016/j.molstruc.2020.129487.

30. Horchani, M.; Hajlaoui, A.; Harrath, A.H.; Mansour, L.; Jannet, H.B.; Romdhane, A. New pyrazolo-triazolopyrimidine derivatives as antibacterial agents: Design and synthesis, molecular docking and DFT studies. Journal of Molecular Structure 2020, 1199, 127007, https://doi.org/10.1016/j.molstruc.2019.127007.

31. Gokalp, M.; Dede, B.; Tilki, T.; Atay, Ç.K.; Triazole based azo molecules as potential antibacterial agents: Synthesis, characterization, DFT, ADME and molecular docking studies, Journal of Molecular Structure 2020, 1212, 128140, https://doi.org/10.1016/j.molstruc.2020.128140.

32. Shahab, S.; Sheikhi, M.; Filippovich, L.; Kumar, R.; Dikusar, E.; H. Yahyaei.; Khaleghian, M. Synthesis, geometry optimization, spectroscopic investigations (UV/Vis, excited states, FT-IR) and application of new azomethine dyes. Journal of Molecular Structure 2017, 1148, 134-149. https://doi.org/10.1016/j.molstruc.2017.07.036.

33. Ali, M.; Mansha, A.; Asim, S.; Zahid, M.; Usman, M.; Ali, N. DFT Study for the Spectroscopic and Structural Analysis of p-Dimethylaminoazobenzene. Journal of Spectroscopy 2018, 2018, 1-15, https://doi.org/10.1155/2018/9365153.

34. Frisch, M.; et. al. Revision B. 01, Gaussian. Inc., Wallingford CT 2010.

35. Luque, F.J.; Zhang, Y.; Aleman, C.; Bachs, M.; Gao, J.; Orozco, M. Solvent effects in chloroform solution: parametrization of the MST/SCRF continuum model. Journal of Physical Chemistry 1996, 100, 4269-4276, https://pubs.acs.org/doi/10.1021/jp9529331.

36. Deka, K.; Phukan, P. DFT analysis of the nucleophilicity of substituted pyridines and prediction of new molecules having nucleophilic character stronger than 4-pyrrolidino pyridine, Journal of Chemical Sciences 2016, 128, 633-647, https://doi.org/10.1007/s12039-016-1057-5.

37. Pearson, R.G. The electronic chemical potential and chemical hardness. Journal of Molecular Structure: THEOCHEM 1992, 255, 261-270, https://doi.org/10.1016/0166-1280(92)85014-C.

38 Chamorro, E.; Chattaraj, P.K.; Fuentealba, P. Variation of the electrophilicity index along the reaction path The Journal of Physical Chemistry A 2003, 107, 7068-7072, https://doi.org/10.1021/jp035435y.

39. Venianakis, T.; Oikonomaki, C.; Siskos, M.G., Varras, P.C.; Primikyri, A.; Alexandri, E.; Gerothanassis, I.P. DFT calculations of $1 \mathrm{H}$-and ${ }^{13} \mathrm{C}-\mathrm{NMR}$ chemical shifts of geometric isomers of conjugated linoleic acid (18: 2 ( -7 -7) and model compounds in solution. Molecules 2020, 25, 3660, https://doi.org/10.3390/molecules25163660.

40. Reed, A.E.; Curtiss, L.A.; Weinhold, F. Intermolecular interactions from a natural bond orbital, donoracceptor viewpoint. Chemical Reviews 1988, 88, 899-926, https://doi.org/10.1021/cr00088a005. 
41. Flores-Holguín, N.; Frau, J.; Glossman-Mitnik, D. Chemical reactivity and bioactivity properties of the Phallotoxin family of fungal peptides based on Conceptual Peptidology and DFT study. Heliyon 2019, 5, e02335, https://doi.org/10.1016/j.heliyon.2019.e02335.

42. Lipinski, C.A. Lombardo, F.; Dominy, B.W.; Feeney, P.J. Experimental and computational approaches to estimate solubility and permeability in drug discovery and development settings. Advanced Drug Delivery Reviews 1997, 23, 3-25, https://doi.org/10.1016/S0169-409X(96)00423-1.

43. Ghose, A.K.; Viswanadhan, V.N.; Wendoloski, J.J. A knowledge-based approach in designing combinatorial or medicinal chemistry libraries for drug discovery. 1. A qualitative and quantitative characterization of known drug databases. Journal of combinatorial chemistry 1999, 1, 55-68, https://doi.org/10.1021/cc9800071.

44. Veber, D.F.; Johnson, S.R.; Cheng, H.Y.; Smith, B.R.; Ward, K.W.; Kopple, K.D. Molecular properties that influence the oral bioavailability of drug candidates. Journal of Medicinal Chemistry 2002, 45, 2615-2623, https://doi.org/10.1021/jm020017n.

45. Shahab, S.; Sheikhi, M.; Filippovich, L.; Khaleghian, M.; Dikusar, E.; Yahyaei, H.; Borzehandani, M.Y. Spectroscopic Studies (Geometry Optimization, E $\rightarrow$ Z Isomerization, UV/Vis, Excited States, FT-IR, HOMO-LUMO, FMO, MEP, NBO, Polarization) and Anisotropy of Thermal and Electrical Conductivity of New Azomethine Dyes in Stretched Polymer Matrix. Silicon 2018, 10, 2361-2385, https://doi.org/10.1007/s12633-018-9773-8.

46. Yan, B.; Gremlich, H.U.; Moss, S.; Coppola, G.M.; Sun, Q.; Liu, L. A comparison of various FTIR and FT Raman methods: applications in the reaction optimization stage of combinatorial chemistry. Journal of combinatorial chemistry 1999, 1, 46-54, https://doi.org/10.1021/cc980003w.

47. Azev, Y.A.; Ermakova, O.S.; Berseneva, V.S.; Bakulev, V.A.; Ezhikova, M.A.; Kodess, M.I. Synthesis of fluoroquinoxalin-2 (1 H)-one derivatives containing substituents in the pyrazine and benzene fragments. Russian Journal of Organic Chemistry 2017, 53, 90-95, https://doi.org/10.1134/S107042801701016X.

48. Huang, X.; Liu, T.; Gu, J.; Luo, X.; Ji, R.; Cao, Y.; Xue, H.; Wong, J.T.F.; Wong, B.L.; Pei, G. 3D-QSAR model of flavonoids binding at benzodiazepine site in GABAA receptors. Journal of Medicinal Chemistry 2001, 44, 1883-1891, https://doi.org/10.1021/jm000557p.

49. Tanak, H. Crystal Structure, Spectroscopy, and Quantum Chemical Studies of (E)-2-[(2Chlorophenyl)iminomethyl]-4-trifluoromethoxyphenol. The Journal of Physical Chemistry A 2011, 115, 13865-13876, https://doi.org/10.1021/jp205788b.

50. Jedinak, A.; Maliar, T. Inhibitors of proteases as anticancer drugs-Minireview. Neoplasma 2005, 52, 185192, https://pubmed.ncbi.nlm.nih.gov/15875078/.

51. Kannaiyan, R.; Mahadevan, D. A comprehensive review of protein kinase inhibitors for cancer therapy. Expert Review of Anticancer Therapy 2018, 18, 1249-1270, https://doi.org/10.1080/14737140.2018.1527688.

52. Ghione, S.; Mabrouk, N.; Paul, C.; Bettaieb, A.; Plenchette, S. Protein kinase inhibitor-based cancer therapies: Considering the potential of nitric oxide (NO) to improve cancer treatment. Biochemical Pharmacology 2020, 176, 113855, https://doi.org/10.1016/j.bcp.2020.113855. 